\title{
A Eucalyptus bacterial wilt isolate from South Africa is pathogenic on Arabidopsis and manipulates host defences
}

\author{
By S. Naidoo ${ }^{1}$, J. Fouche'-Weich ${ }^{1}$, P.Law ${ }^{2}$, K. J. Denby ${ }^{3}$, Y. Marco ${ }^{4}$ and D. K. Berger ${ }^{1,5}$ \\ ${ }^{1}$ Department of Plant Science, Forestry and Agricultural Biotechnology Institute (FABI), University of Pretoria, \\ Pretoria 0002, South Africa; \\ ${ }^{2}$ ACGT Bioinformatics and Computational Biology Unit, Department of Biochemistry, University of Pretoria, \\ Pretoria, South Africa; \\ ${ }^{3}$ Warwick HRI and Warwick Systems Biology Centre, University of Warwick, UK; \\ ${ }^{4}$ Laboratoire des Interactions Plantes-Microorganismes (LIPM), UMR CNRS/INRA, Toulouse, France; \\ ${ }^{5}$ E-mail: dave.berger@fabi.up.ac.za (for correspondence)
}

\section{Summary}

Ralstonia solanacearum, the causal agent of bacterial wilt, has been reported from Eucalyptus plantations in at least three countries in Africa. The lack of genomics resources in Eucalyptus species led us to develop and study a pathosystem between a previously characterized South African isolate and the model plant Arabidopsis thaliana. Ralstonia solanacearum BCCF401 isolated from a Eucalyptus grandis $\times$ Eucalyptus camaldulensis hybrid was shown to cause disease on $A$. thaliana ecotype Col-5. Arabidopsis genomics tools were exploited to investigate gene expression changes during wilt disease development, and thereby develop hypotheses that can be tested in Eucalyptus once genomics resources are available. Transcriptome analysis using $5000 \mathrm{~A}$. thaliana ESTs was performed and revealed 141 genes that were differentially regulated by $R$. solanacearum infection (at a significance threshold of $p<0.03$; Bonferroni corrected). A software tool 'Rank Correlation Comparer' was developed to compare expression profiles with Arabidopsis Affymetrix NASCArray data. High correlations were observed between the response of Arabidopsis plants to both Eucalyptus (BCCF401) and tomato (GMI1000) isolates of $R$. solanacearum, as well as to Pseudomonas syringae, Botrytis cinerea and treatment with abscisic acid. Basal defence responses in Col-5 in response to $R$. solanacearum were investigated by comparing the expression data following $R$. solanacearum infection to data after treatment with the Pathogen Associated Molecular Patterns (PAMP) flg22 and lipopolysaccharide, and the Type Three Secretion System deficient Pseudomonas syringae pv. tomato rrp $^{-}$mutant. A subset of the genes which were induced by PAMPs were repressed by $R$. solanacearum infection, and vice versa, suggesting that these genes may be repressed or induced, respectively, by specific $R$. solanacearum effectors. We hypothesize that these genes represent targets of $R$. solanacearum effectors. The pending release of the 
Eucalyptus genome sequence will enable orthologues to be identified and these hypotheses to be tested in Eucalyptus trees.

\section{Introduction}

Ralstonia solanacearum is considered to be one of the most important plant pathogenic bacteria, causing bacterial wilt disease on a broad range of hosts including woody plants such as Eucalyptus, Casuarina, mulberry and olive trees (Coutinho et al. 2000; Xu et al. 2009). Eucalyptus species have been reported as a host for the pathogen in Brazil, China, Taiwan, Australia and Venezuela (Coutinho et al. 2000; Xu et al. 2009). In Africa, $R$. solanacearum poses a threat to the forestry industry as the disease was detected in Eucalyptus plantations in South Africa, Uganda and the Democratic Republic of Congo (Coutinho et al. 2000; Roux et al. 2001; Fouché-Weich et al. 2006). The severity of the disease in Africa may be underestimated as a limited number of Eucalyptus plantations have been surveyed. The pathogen infects both cutting and ramets (individuals which originate vegetatively from a single ancestor), preventing the vegetative propagation of hybrids of Eucalyptus grandis $\times$ Eucalyptus camaldulensis commonly used for pulp and paper production in South Africa (Coutinho et al. 2000). The presence of the pathogen in Eucalyptus plantations is a cause for concern as Eucalyptus is increasingly clonally propagated (Coutinho et al. 2000). It is possible that entire plantations could be lost due to susceptibility of the clone to a particular pathogen.

Eucalyptus plantations are most susceptible to bacterial wilt within the first 2 years of growth, and most commercially grown hybrids are susceptible (Ran et al. 2005a,b). Selection and breeding for resistance is the most attractive long term solution, although glasshouse experiments have indicated that treatment with biocontrol agents (Pseudomonas spp.) or salicylic acid can suppress disease development in the susceptible species Eucalyptus urophylla (Ran et al. 2005a,b).

Observations of the infection process using microscopy have revealed aspects of bacterial wilt disease progression, particularly in the tomato pathosystem (Vasse et al. 2000). The pathogen enters the host via root wounds or sites of secondary root emergence and moves towards the xylem vessels where it multiplies and spreads (Salanoubat et al. 2002). The root cortex and vascular parenchyma are colonised and cell walls are disrupted as a result of the extracellular products such as extracellular polysaccharide, which facilitates the spread of the pathogen through the vascular system, and several plant cell wall-degrading enzymes, which result in the accumulation of cellular debris. This effectively destroys the plants vascular system. Once the plant's water-uptake system is compromised, the plants wilt completely (Genin and Boucher 2002b).

Ongoing molecular studies are revealing elements of pathogenicity mechanisms of $R$. solanacearum (Poueymiro and Genin 2009). The genome sequence of the tomato isolate of $R$. solanacearum (GMI1000) revealed a battery of putative virulence factors/effectors encoded on pathogenicity islands characterized by Alternate Codon Usage Regions and similarity to Type Three Secretion System (TTSS) effectors (Genin and Boucher 2002b; 
Salanoubat et al. 2002). Subsequently, a range of functional studies have revealed hostspecific and broad spectrum $R$. solanacearum effectors in studies of tomato, tobacco, lettuce, pepper, cotton and A. thaliana (Poueymiro and Genin 2009; Wroblewski et al. 2009).

Arabidopsis thaliana has been adopted as a model system to study various plant-pathogen interactions as a result of the lack of genomic and pathosystem resources in natural hosts. The use of $A$. thaliana as a host for the $R$. solanacearum pathogen was previously demonstrated by Deslandes et al. (1998) who showed that the tomato isolate of R. solanacearum (GMI1000) was pathogenic on ecotype Col-5 and did not cause disease on ecotype $\mathrm{Nd}-1$. Subsequent expression studies of the susceptible interaction between Col-5 and GMI1000 using whole-genome microarray analysis revealed that the tomato pathogen induces abscisic acid (ABA) and pathogen-associated molecular pattern (PAMP) responses (Hu et al. 2008).

Studies in $A$. thaliana have been very useful in describing the integrated set of plant defences, and many of these constitutive or induced responses may be conserved between many species (Thatcher et al. 2005). Pathogens that are able to overcome constitutive antimicrobial compounds and structural barriers encounter an induced response that is triggered by the recognition of pathogen-derived elicitors, which may be general (e.g. PAMPs) or race specific (e.g. effectors, such as Avr proteins). The elicitors and effectors are perceived by receptors located either at the cell surface or inside the cell (Dardick and Ronald 2006). Pathogen recognition by the plant results in a series of signalling cascades that involve the signalling molecules salicylic acid (SA), jasmonic acid (JA) and ethylene (ET). There is a tendency for plants to rely on the JA and ET signalling pathways for resistance against necrotrophic pathogens and on the SA signalling pathway for resistance against biotrophic pathogens (Thomma et al. 1999). Activation of these defence pathways are also observed in susceptible plants; however, at a later stage and/or to a lower intensity than during a resistant interaction (Tao et al. 2003).

A basal defence response also develops in susceptible plants treated with general elicitors [i.e. PAMPs such as bacterial lipopolysaccharides (LPS), flagellin, cold-shock protein and elongation factor Tu, as well as fungal glucan and chitin]. However, these responses are insufficient to prevent disease onset (Jones and Dangl 2006). LPS from Gram-negative bacteria induce an oxidative burst and the production of antimicrobial enzymes in pepper and tobacco (Newman et al. 2000; Meyer et al. 2001). The pretreatment of plants with LPS results in the enhancement of the plant's defence response to subsequent pathogen challenge and LPS was able to potentiate the expression of $P R$ genes upon subsequent bacterial inoculation (Newman et al. 2000). Flg22, a 22 amino acid peptide found at the Nterminus of flagellin, the subunit of the bacterial surface structure flagellum, is able to induce a defence response in plants to a higher level than flagellin itself (Felix et al. 1999). In some cases, bacterial PAMPs may not be detected by the host, e.g. although $R$. solanacearum possesses flagellin, it is not responsible for the activation of a defence response in Arabidopsis (Pfund et al. 2004). Arabidopsis plants challenged with the wildtype and aflagellate $R$. solanacearum strains of isolate K60 showed similar disease levels regardless of whether they contained the flagellin receptor FLS2 or not. 
Microarray expression profiling in Arabidopsis has shown that PAMPs such as flg22 and LPS induce basal defence responses and that the responses induced by both these PAMPs overlap to some extent (Zeidler et al. 2004). Experiments on Arabidopsis plants challenged with mutants of bacterial pathogens deficient in the TTSS pathway ( $h r p^{-}$) and wild-type bacterial pathogens suggest that specific effector proteins from the pathogen are able to suppress host basal defences, which are otherwise induced by PAMPs, to cause disease (Thilmony et al. 2006; Truman et al. 2006). This is reinforced by studies demonstrating that some effectors can indeed suppress basal immunity, for example hopPtoM and avrE genes of $P$. syringae encode suppressors of salicylic acid mediated basal immunity (Debroy et al. 2004).

Our current study builds on previous work in which $R$. solanacearum was reported for the first time from E. grandis $\times$ E. camaldulensis plantations in South Africa (Coutinho et al. 2000). Subsequently, the same isolate (BCCF401), as well as Eucalyptus isolates from two other African countries (Uganda and Democratic Republic of Congo) were confirmed to be biovar 3 (Fouché-Weich et al. 2006). Importantly, although they are both biovar 3 , the Eucalyptus isolate BCCF401 from South Africa in this study is distinct from the wellcharacterized tomato isolate GM1000 from French Guyana based on PCR-RFLP and AFLP analysis (Fouché-Weich et al. 2006). In the current study, we have characterized the plant response to this Eucalyptus isolate BCCF401 using an A. thaliana pathosystem. Genomics resources were limited for Eucalyptus, and therefore we chose to use Arabidopsis as a model system, which would facilitate translation of the results to the tree host once the annotated Eucalyptus genome sequence is released (planned for 2010, Myburg et al. 2008).

We have shown that the Eucalyptus $R$. solanacearum isolate BCCF401 was pathogenic on A. thaliana ecotype Col-5. Based on the observed susceptibility, this interaction was investigated in a microarray experiment profiling the expression of approximately $20 \%$ of the Arabidopsis genome. The aim was to determine the gene expression changes that take place in the plant during infection. We used bioinformatics tools to compare our data with publicly available microarray data, which illustrated that there was substantial overlap in the response of Arabidopsis plants to $R$. solanacearum isolates from Eucalyptus and tomato. However, we also obtained evidence for manipulation of basal defence responses, and isolate-specific responses which we hypothesize are targets of host-specific effectors. Our data provide useful leads for future work to characterize the response in Eucalyptus trees, which will be greatly facilitated by the release of the annotated Eucalyptus genome sequence (Myburg et al. 2008). Orthologues to Arabidopsis genes that are putative targets of $R$. solanacearum BCCF401 effectors can then be identified using phylogenomic approaches (Cao et al. 2008).

\section{Materials and methods}

\subsection{Plant material}

Seeds of Arabidopsis ecotype Col-5 were obtained from the Nottingham Arabidopsis Stock Centre (NASC, http://www.arabidopsis.info) and sterilized with $70 \%$ ethanol, $1.5 \%$ sodium hypochlorite and washed in sterile distilled water. Seeds were germinated on Murashige and Skoog (1962) medium for 2 weeks under $16 \mathrm{~h}$ day conditions. The plants were 
transferred to Jiffy pots (Jiffy France, Lyon, France) and grown for 4 weeks under $16 \mathrm{~h}$ light, $25-26^{\circ} \mathrm{C}, 50 \%$ relative humidity and $200-250 \mu \mathrm{moles} / \mathrm{m}^{2} / \mathrm{s}$. The plants were watered with a solution of Feedall ${ }^{\circledR}$ [Aquasol (Pty) Ltd, Potchefstroom, SA, USA] once a week.

\subsection{Bacterial isolates and growth media}

Ralstonia solanacearum isolates BCCF401 from E. grandis $\times$ E. camaldulensis clones in South Africa (Coutinho et al. 2000; Fouché-Weich et al. 2006) or GMI1000 (Boucher et al. 1985; Deslandes et al. 1998) were grown on solidified Bacto-agar Glucose Triphenyltetrazolium chloride (BGT) media at $28^{\circ} \mathrm{C}$ for $48 \mathrm{~h}$. Colonies that displayed a virulent phenotype (mucoid) were transferred to liquid $\mathrm{B}$ media (Boucher et al. 1985) and incubated overnight at $28^{\circ} \mathrm{C}$. To prepare the rifampicin mutant, two colonies of BCCF401 were picked from a fresh culture (16-24 h) on BGT medium and subjected to overnight incubation in B broth. After centrifugation, the pellet was spread on BGT medium containing rifampicin $(50 \mu \mathrm{g} / \mathrm{ml})$ and glucose (0.5\%). The plates were incubated for 3 days at $28^{\circ} \mathrm{C}$. Single rifampicin resistant wild-type like, mucoid colonies were selected and overnight broth cultures were prepared (named BCCF401*).

Preparation of the BCCF401 $\mathrm{hrp}^{-}$mutant involved the extraction of genomic DNA from $h r p^{-} R$. solanacearum strain GMI1402, a derivative of GMI1000 carrying a disruption in the hrcS (hrp-conserved) gene (Arlat et al. 1992). The receiver strain BCCF401 was grown for 3 days in minimal media [one-quarter strength M63 (Maniatis et al. 1982), with a final concentration of $2 \%$ glycerol], on a rotary shaker at $30^{\circ} \mathrm{C}$. When an optical density of 1 was obtained, the bacterial growth solution was placed on a nitrocellulose filter on B medium without glucose and incubated with $0.3 \mu \mathrm{g} / \mu \mathrm{l}$ total genomic DNA of GMI1402. Incubation was carried out at $30^{\circ} \mathrm{C}$ for $2-3$ days. The bacterial growth was collected by quick centrifugation of the nitrocellulose filter using $1 \mathrm{ml}$ of sterile distilled water. The filter was removed and the remaining suspension mixed by vortexing. One hundred microlitres of this suspension was streaked onto a selection plate of BGT medium containing $50 \mu \mathrm{g} / \mathrm{ml}$ kanamycin. Incubation followed at $30^{\circ} \mathrm{C}$ for $2-3$ days. The $h r p^{-}$mutants that were no longer capable of inducing a hypersensitive response on tobacco were chosen (data not shown).

\subsection{Bacterial inoculations and disease scoring}

Inoculations were performed according to Deslandes et al. (1998). Briefly, the Jiffy pots containing the Arabidopsis plants were cut horizontally through the middle to wound and expose the roots and soaked in a solution of bacteria $\left(1 \times 10^{8} \mathrm{cfu} / \mathrm{ml}\right)$ for $30 \mathrm{~min}$. Control plants were soaked in a solution of liquid $\mathrm{B}$ media without any bacteria. The plants were placed on moist vermiculite and maintained at $26^{\circ} \mathrm{C}, 60-70 \%$ humidity and $16 \mathrm{~h}$ day length.

The plants were rated on a scale from 0 (no disease) to 4 ( $100 \%$ wilted/dead plants) according to the method of Deslandes et al. (1998), where wilt symptom 0.5 was descriptive of plants showing less than $12 \%$ of the leaves wilted; symptom 1 , less than $25 \%$ of the leaves wilted; symptom 2, less than $50 \%$ of the leaves wilted; symptom 3, 50-75\% of the leaves wilted and symptom $4,76-100 \%$ of the plant was wilted/dead. The data were used to calculate the Disease Index using the formula, $\mathrm{DI}=\left[\sum\left(\mathrm{n}_{\mathrm{i}} \times \mathrm{v}_{\mathrm{i}}\right) /(\mathrm{V} \times \mathrm{N})\right]$, where $\mathrm{DI}=$ Disease Index; $n_{i}=$ number of plants with respective disease rating; $v_{i}=$ disease rating $(0,1,2,3$ or 
4); $\mathrm{V}=$ the highest disease rating (4) and $\mathrm{N}=$ the number of plants observed (Winstead and Kelman 1952).

Bacterial enumerations were carried out as described by Deslandes et al. (1998) with selection for $R$. solanacearum BCCF401* and GMI1000 on $50 \mu \mathrm{g} / \mathrm{ml}$ rifampicin and BCCF401 hrp- mutant on $50 \mu \mathrm{g} / \mathrm{ml}$ kanamycin.

\subsection{RNA isolation}

Total RNA was isolated from aerial parts of 8-12 control and infected plants per biological replicate using TriReagent (Sigma Aldrich, St Louis, Missouri, USA) according to the manufacturer's instructions and further purified using the Qiagen RNeasy Plant Mini Kit (Qiagen, Valencia, CA, USA). mRNA was isolated using the OligoTex mRNA Isolation Kit (Qiagen). RNA yield was determined by measuring absorbency at $260 \mathrm{~nm}$, using a Nanodrop ND-100 Spectrophotometer (Nanodrop Technologies, Inc., Montchanin, DE, USA).

\subsection{Microarray experiments}

The experimental design consisted of a direct comparison between control and inoculated samples at different times after inoculation with the bacteria (early and late). Two biological experiments were performed and a technical replicate (with reversion of the dye assignments) was carried out for both of these. Four slides per symptom (early wilt or late wilt) were hybridised. Figure S1 shows the experimental design that was used. Corning Gap II slides consisting of 7200 Arabidopsis cDNA elements (from the Mendel Biotechnology L35 collection) were purchased from the University of Cape Town, South Africa (capar). The identities of the array elements are included in NCBI GEO database (accession no. GSE19178). Labelling, hybridisations, scanning and data capture were conducted as described in Naidoo et al. (2007).

Gene expression data were normalized and significant gene expression differences identified using the mixed model anova approach of Wolfinger et al. (2001). The data were corrected for multiple testing using the Bonferroni correction and volcano plots were generated for both wilting conditions. Those genes with a $\log _{2}$-fold change greater than 0.75 or less than -0.75 with $a-\log _{10} p>1.5(p<0.03)$ were selected as differentially expressed in response to the infection. Microarray data have been deposited in the NCBI GEO database (GSE19178).

\subsection{Reverse transcription quantitative PCR}

Two-step reverse-transcription quantitative PCR (RT-qPCR) was performed using a LightCycler instrument (Version 1.2; Roche Diagnostics GmbH, Mannheim, Germany). PCR primers were designed using Primer Designer version 4 (Scientific \& Educational Software, Cary, NC, USA). Primer sequences are as follows: PR-3 (At3g12500) forward 5'GACTGCTCAGCCTCCCAAAC3' and reverse 5'ATACGATCGGCGACTCTCCC3'; Sip1 (At3g57520) forward 5'CGATAACCGTTCTCCAACAG3' and reverse 5'AAAGTCAAGCCCAACCTC3'; TAT (At5g53970) forward 5'TTCCTCGCATCGACCAGAAG3' and reverse 5'AGTTGCATCTGCTGCAAACG3'; OEC23 (At1g06680) forward 
5'CAACAATGCAGTGGCAACAG3' and reverse 5'GCTTGTGCTTTGCAGATGTC3'. PR-4 primers were from the purchased Primer library for Arabidopsis Pathogen-inducible Genes (Sigma). Two micrograms of total DNasel-treated and column-purified RNA extracted from treated and control plants were reverse transcribed into first strand cDNA using Impromll reverse transcriptase (Promega, Madison, WI, USA) according to manufacturer's instructions. The LightCycler FastStart DNA Master ${ }^{\text {PLUS }}$ SYBR Green I system (Roche) was used for real-time PCR in a $20 \mu \mathrm{l}$ reaction. All PCR reactions were performed in duplicate and a biological replicate was included. Relative quantification was performed with the LightCycler software (version 3.5.3; Roche) using the Second Derivative Maximum method. For normalizing expression levels, the Cap Binding Protein (CBP) 20 gene (Sigma) or the elongation factor-1alpha-related GTP binding protein factor (W43332, At1g18070.1, forward 5'TGCGGTTGTCGAGGAGTGGTG3' and reverse 5'AACCCGAAAGCCGTCTCCTG3') were used. The elongation factor-1-alpha-related GTP binding protein factor gene was expressed constitutively in microarray experiments ( $\log _{2}$-fold change $\sim 0$, and $p$-value $=0.0003$, late wilt expression profile) and showed constitutive expression in most biotic stress conditions tested based on Affymetrix microarray data available on GENEVESTIGATOR (Zimmermann et al. 2005). In all cases tested, normalisation using either the CBP 20 gene or elongation factor-1-alpha-related GTP binding protein factor gene produced similar results (results not shown). Cycling consisted of a $95^{\circ} \mathrm{C}$ activation step for $10 \mathrm{~min}, 40$ cycles of $95^{\circ} \mathrm{C}$ for $30 \mathrm{~s}$, annealing temperature specific for each primer combination and an extension of $72^{\circ} \mathrm{C}$ for $2 \mathrm{~min}$. Data acquisition was performed between $72^{\circ} \mathrm{C}$ and $80^{\circ} \mathrm{C}$. Melting curve analysis and agarose gel electrophoresis of the RT-qPCR products were performed to confirm that the individual RT-qPCR products corresponded to a single homogenous CDNA fragment of expected size. All amplicons were sequenced to confirm that the correct gene was targeted.

\subsection{Gene ontologies}

Over-represented GO terms in the category biological process were determined using GOStat (Beißbarth and Speed 2004) by comparing to the GO terms of the 5000 unigenes represented on the microarray and to that of the whole genome (TAIR7 release). A chisquared test or a Fischer's exact test was used to approximate the $p$-value that represents the probability that the observed number of counts of each $\mathrm{GO}$ term could have resulted by randomly distributing this $\mathrm{GO}$ term between the tested group and the reference group. The error rate inadvertently generated by multiple testing was controlled using the Holm correction.

\subsection{Bioinformatics comparison of expression data with NASCArrays data}

\subsubsection{Rank correlation comparer}

The microarray expression data for selected genes from early wilt and late wilt stages of infection with BCCF401 was compared with the NASCArrays Arabidopsis Affymetrix database to identify experiments with similar expression profiles. The tool Rank Correlation Comparer (RCC) was developed for this purpose within the web-based 'MicroArray Data Interface for Biological Annotation' (MADIBA) (Law et al. 2008). Affymetrix experimental data from NASCArrays were stored within the MADIBA database (http://www.bi.up.ac.za/MADIBA/). In each NASCArrays experiment, the ratio of the 
expression level in the test case to the expression level in the corresponding control case (no treatment or $0 \mathrm{~h}$ time-point) was calculated and log2-transformed. The median of all replicate values was calculated. The expression of the submitted genes across each experiment was extracted and ranked in order of expression ratios. A Spearman rank correlation coefficient between the submitted data and each experiment stored in the database was calculated using RCC (http://www.bi.up.ac.za/MADIBA/organisms.php).

\subsubsection{Comparison with basal defences}

Microarray expression data for 120 of 134 genes that were differentially expressed in A. thaliana in response to $R$. solanacearum BCCF401 were extracted from selected experiments in NASCARRAYS. These experiments represented responses to the Pathogen Associated Molecular Patterns (PAMPs) flg22 and lipopolysaccharide (LPS), and to a nonvirulent Pst $h r p^{-}$mutant, virulent Pst DC3000 and $R$. solanacearum GMI1000. Replicate data within each NASCARRAYS dataset was averaged, and $\log _{2}$-fold change was calculated for each gene at each treatment and time-point relative to the relevant controls using Microsoft ${ }^{\oplus}$ Excel 2002 (Microsoft, Redmond, WA, USA). TIGR MultiExperiment Viewer (MeV) (Saeed et al. 2003) was used to cluster the complete dataset. Basal defence response genes were selected if they were induced/repressed by PAMP treatments (flg22, LPS or other PAMPs represented by Pst $h r p^{-}$treatment) or virulent pathogens (Pst DC3000, $R$. solanacearum BCCF401, or $R$. solanacearum GMI1000). The accepted threshold for induced and repressed genes was a $\log _{2}$ fold change greater than 0.75 and less than -0.75 , respectively.

\section{Results}

\subsection{Eucalyptus isolate of Ralstonia solanacearum is virulent on Arabidopsis thaliana}

The bacterial wilt isolate BCCF401 from an E. grandis $\times E$. camaldulensis plantation in KwaZulu Natal, South Africa (Coutinho et al. 2000; Fouché-Weich et al. 2006) was able to cause disease on Arabidopsis thaliana ecotype Col-5. Susceptibility was confirmed in at least three independent experiments. Col-5 plants showed wilt symptoms approximately 10 days after inoculation. Wilt symptom 1-2 was observed 7-10 days after infection (Fig. 1a(ii) and (iii); early wilt) while wilt symptom 3-4 was observed 15-20 days post-infection (Fig. 1a(iv) and (v); late wilt). Disease index scores showed that $R$. solanacearum $\mathrm{GMI} 1000$, an isolate from tomato (Boucher et al. 1985) was more virulent than BCCF401 on A. thaliana ecotype Col-5 (Fig. 1b). Ecotype Nd1, in comparison to Col-5, was resistant to both GMI1000 and BCCF401 (Fig. 1b). Inoculation of Col-5 with a hrp $^{-}$strain of BCCF401 resulted in no disease development (Fig. 1C; Fig. S2). Bacterial numbers reached $1 \times 10^{11}$ in Col-5 plants infected with BCCF401 but remained at $1 \times 10^{7}$ in Col-5 plants inoculated with the $h r p^{-}$strain of BCCF401 and in the control-resistant interaction between ecotype Nd-1 and BCCF401 (Fig. 1C; Fig. S2). This suggests that disease development is $h r p$-dependent, requires multiplication of the bacteria, and is not simply due to a toxin from the pathogen. 

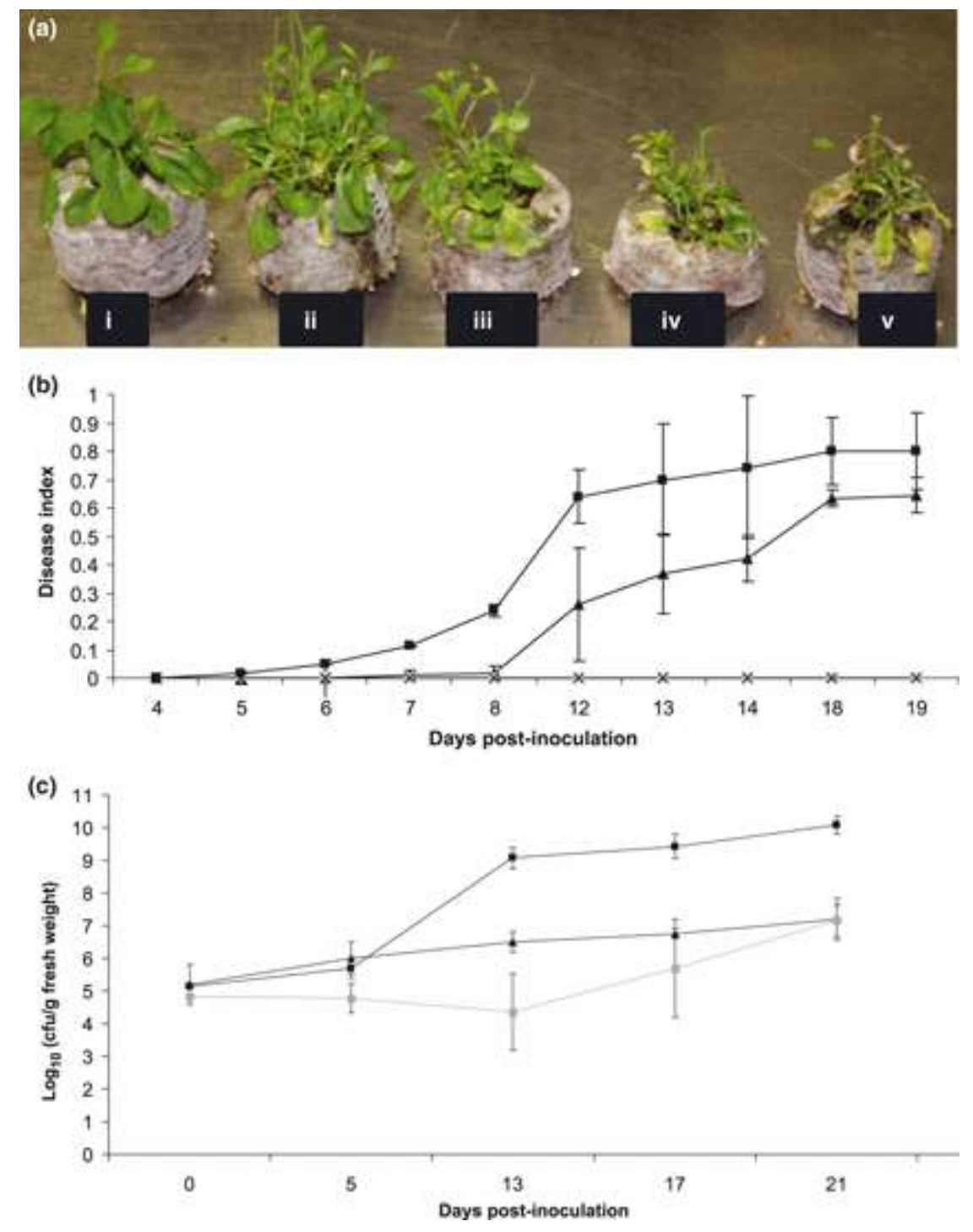

Figure 1. Susceptibility of Arabidopsis thaliana ecotypes to Ralstonia solanacearum. (a) Wilt symptoms on Col5 inoculated with $1 \times 10^{8} \mathrm{cfu} / \mathrm{ml}$ of $R$. solanacearum BCCF401 using a root-inoculation method. The control plants were inoculated with a suspension of media and water.(i) Healthy control plant, no wilt symptom; plant showing wilt symptom 1 (ii), 2 (iii), 3 (iv) and 4 (v). (b) Disease index for Arabidopsis ecotypes infected with isolates of $R$. solanacearum. Ecotype Col-5 inoculated with $R$. solanacearum GMI1000 ( $\square$ ), ecotype Col-5 inoculated with BCCF $401(\boldsymbol{A})$, ecotype Nd-1 after challenge with GMI1000 ( ) and ecotype Nd-1 after challenge with BCCF $401(x)$. The disease index for each treatment was calculated based on data from 14 individual plants over 20 days. Replicate infection experiments yielded similar results. (c) Bacterial numbers in Arabidopsis ecotypes inoculated with $R$. solanacearum. Ecotype Col-5 infected with $R$. solanacearum BCCF 401* ( $\mathbf{(})$, ecotype Col-5 infected with the hrp ${ }^{-}$mutant of BCCF 401 ( $\mathbf{A}$ ) and ecotype Nd-1 inoculated with $R$. solanacearum isolate BCCF 401* ( ). Bacterial counts were calculated on nine plants per time-point. $R$. solanacearum BCCF $401^{*}$ is a spontaneous rifampicin resistant mutant of $R$. solanacearum BCCF 401 used to ensure that only $R$. solanacearum colonies were counted.

\subsection{Eucalyptus and tomato isolates of $R$. solanacearum elicit similar expression profiles in Arabidopsis}

cDNA microarray expression profiling of $A$. thaliana Col-5 plants inoculated with $R$. solanacearum BCCF401 and sampled at early wilt and late wilt stages separately was carried out in replicate experiments. A mixed model anova analysis (Wolfinger et al. 2001; 
Adie et al. 2007) revealed 141 genes that were significantly up or down-regulated using stringent selection criteria ( $\log _{2}$-fold change $>0.75$ or $<-0.75 ; p<0.03-$ Bonferroni corrected) (Fig. 2; Table S1). A greater proportion of genes were differentially expressed at the late wilt stage (72\%) (Fig. 2). The cDNA microarray slides used for profiling contained 5000 Unigenes obtained from EST collections, representing approximately $20 \%$ of the Arabidopsis genome. There was no significant overrepresentation of GO terms on the microarray although $28 \%$ and $29 \%$ of genes on the microarray are annotated as responsive to abiotic/biotic stimulus and to stress, respectively, relative to the whole genome (Table S2). Although $R$. solanacearum is a root pathogen, in this study, aerial parts of the plant (leaf and stem) were selected for analysis as the root tissues of the plants were difficult to obtain from the Jiffy pots and at the later wilt symptoms, roots became damaged by infection and were insufficient for microarray profiling experiments. It has previously been shown that leaf inoculations of $R$. solanacearum in Arabidopsis illicit similar wilting symptoms to that observed by root inoculation (Deslandes et al. 1998).

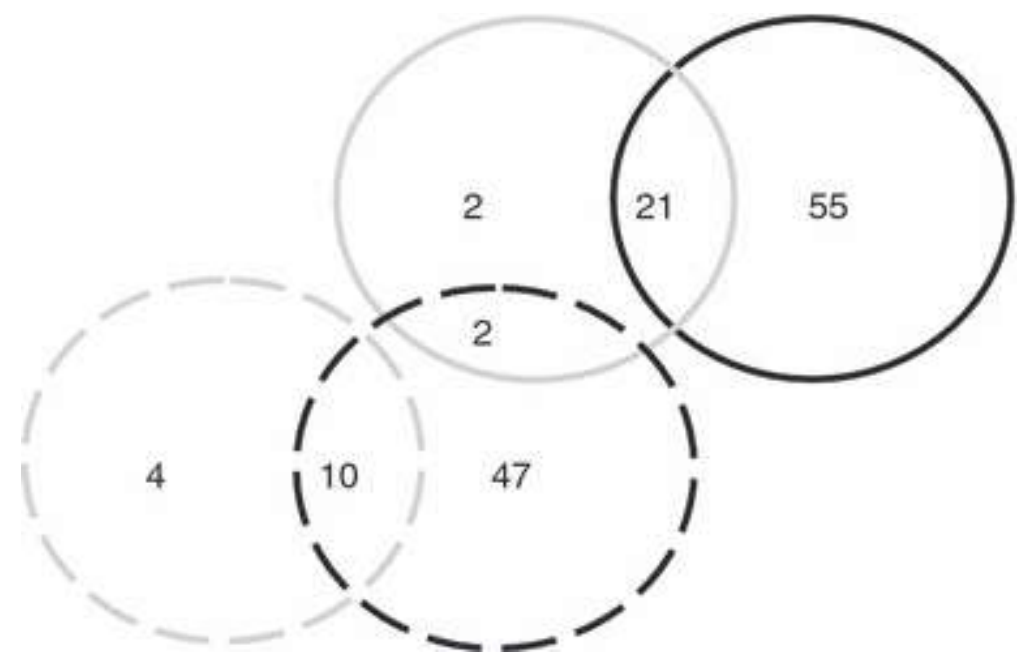

Figure 2. Venn diagram representing up-regulated (solid lines) and down-regulated (dashed lines) gene sets in early (grey circles) and late wilt stages (black circles) in response to Ralstonia solanacearum BCCF 401 infection. Genes were selected following mixed model anova analysis. Only those genes considered significantly up- and down-regulated are represented ( $\log _{2}$ fold change $>0.75$ or $<-0.75$, respectively; $p$ value $<0.03$ ).

Microarray expression data from the susceptible $A$. thaliana- $R$. solanacearum BCCF401 interaction were compared with data from other $A$. thaliana treatments. The RCC tool was developed for this purpose (http://www.bi.up.ac.za/MADIBA/organisms.php). Late wilt expression ratios for all genes that showed consistent expression across replicates (218 genes; anova analysis, $p<0.03$ ) were submitted to RCC for comparison to expression data from Arabidopsis NASCArrays. Experiment comparisons are carried out in RCC based on the ranks of expression ratios, rather than the expression ratios themselves, to better account for differences in the microarray platforms. The highest correlation during late wilt responses (0.71) was obtained with expression data from infection of $A$. thaliana Col-5 plants with the $R$. solanacearum isolate GMI1000 from tomato (Table 1). The correlation between the early wilt responses in Col- 5 by BCCF401 and GMI1000 was 0.6 (data not shown). This suggests conservation of virulence strategies by $R$. solanacearum isolates from different hosts. Top ranking correlations were also shown to compatible interactions with Pseudomonas syringae and Botrytis cinerea (Table 1). Interestingly, there were also high 
correlations with two independent ABA treatments (Table 1), lending support to previous reports that $A B A$ is involved in the plant response to bacterial wilt (Hernandez-Blanco et al. 2007). Correlation was also observed with expression data from the resistant response of Arabidopsis plants to $R$. solanacearum GMI1000, which may reflect similarities between the early resistant response and late susceptible responses, as has been observed in other plant-pathogen interactions (Tao et al. 2003).

Table 1. NASCArrays experiments with expression profiles similar to the late wilt expression profile induced by $R$. solanacearum BCCF401 infection in Arabidopsis.

\begin{tabular}{|c|c|c|c|c|c|}
\hline $\begin{array}{l}\text { NASCARRAY } \\
\text { reference }\end{array}$ & Experiment name & Experiment description & Control & p-value & $\begin{array}{c}\text { Rank }^{1} \\
\text { correlation }^{1}\end{array}$ \\
\hline 447 & Marco_Col-1000-D3 & $\begin{array}{l}\text { Compatible interaction } R s o l \\
\text { GMI1000 t = } 8 \text { days }\end{array}$ & $t=0$ & $\begin{array}{l}1.05 E- \\
31\end{array}$ & 0.71 \\
\hline 447 & $\begin{array}{l}\text { Marco_Nd-DeltaPopP2- } \\
\text { D3 }\end{array}$ & $\begin{array}{l}\text { Compatible interaction } R s o l \\
\text { GMI1000 t = } 8 \text { days }\end{array}$ & $t=0$ & $\begin{array}{l}3.96 \mathrm{E}- \\
24\end{array}$ & 0.64 \\
\hline 447 & Marco_Col-1000-D1 & $\begin{array}{l}\text { Compatible interaction } R s o l \\
G M I 1000 \mathrm{t}=5 \text { days }\end{array}$ & $t=0$ & $\begin{array}{l}1.32 \mathrm{E}- \\
21\end{array}$ & 0.61 \\
\hline 120 & $\begin{array}{l}\text { AtGen_A-13_23- } \\
\text { 1_REP1_ATH1 }\end{array}$ & $\begin{array}{l}\text { Compatible interaction Pst } \\
D C 3000 \mathrm{t}=24 \mathrm{~h}\end{array}$ & Untreated & $\begin{array}{l}3.83 E- \\
20\end{array}$ & 0.59 \\
\hline 447 & $\begin{array}{l}\text { Marco_Nd-DeltaPopP2- } \\
\text { D1 }\end{array}$ & $\begin{array}{l}\text { Compatible interaction } R \text { sol } \\
\text { GMI1000 t = } 5 \text { days }\end{array}$ & $t=0$ & $\begin{array}{l}3.07 E- \\
19\end{array}$ & 0.58 \\
\hline 120 & $\begin{array}{l}\text { AtGen_A-25_26- } \\
\text { 1_REP1_ATH1 }\end{array}$ & $\begin{array}{l}\text { Incompatible interaction Pst } \\
\text { avrRpm } 1 \mathrm{t}=24 \mathrm{~h}\end{array}$ & Untreated & $\begin{array}{l}1.71 \mathrm{E}- \\
17\end{array}$ & 0.56 \\
\hline 176 & RIKEN-GODA21A & $\mathrm{ABA}$ treatment $\mathrm{t}=3 \mathrm{~h}$ & Untreated & $\begin{array}{l}4.94 \mathrm{E}- \\
15\end{array}$ & 0.52 \\
\hline 447 & Marco_Nd-1000-D1 & $\begin{array}{l}\text { Incompatible interaction } R \text { sol } \\
\text { GMI1000 t = } 5 \text { days }\end{array}$ & $t=0$ & $\begin{array}{l}2.42 \mathrm{E}- \\
14\end{array}$ & 0.51 \\
\hline 447 & Marco_Nd-1000-D3 & $\begin{array}{l}\text { Incompatible interaction } R s o l \\
\text { GMI1000 t = } 8 \text { days }\end{array}$ & $t=0$ & $\begin{array}{l}2.31 \mathrm{E}- \\
13\end{array}$ & 0.49 \\
\hline 167 & BC482-1 & $\begin{array}{l}\text { Compatible interaction Botrytis } \\
\text { cinerea } \mathrm{t}=48 \mathrm{~h}\end{array}$ & Untreated & $\begin{array}{l}2.69 E- \\
13\end{array}$ & 0.49 \\
\hline 57 & Okamoto_gpa1-treated & ABA treatment $t=3 \mathrm{~h}$ & Untreated & $\begin{array}{l}1.07 \mathrm{E}- \\
11\end{array}$ & 0.46 \\
\hline
\end{tabular}

${ }^{1}$ The highest rank correlation results from the RCC Tool (http://www.bi.up.ac.za/MADIBA/organisms.php) are indicated.

GOstat analysis for the category biological process (Beißbarth and Speed 2004) of the gene lists indicated that both biotic (response to other organisms; innate immune response, JA and ET-dependent defence responses) and abiotic (response to water deprivation) stress responses were induced by $R$. solanacearum infection during early (Table 2 ) and late wilt (data not shown). A significant number of genes had common GO terms and were identified as over-represented GO terms ( $p<0.05$; Holm corrected) relative to the 5000 unigenes on the microarray, and to the whole Arabidopsis genome (Table 2). Each percentage indicates the proportion of that $\mathrm{GO}$ term which is found in the up-regulated gene set relative to the proportion of that $\mathrm{GO}$ term found on the 5000 unigene microarray or in the whole genome. 
Table 2. Over-represented GO terms in the category biological process for early wilt up-regulated genes in comparison to the 5000 unigenes represented on the microarray and to the whole genome using GOStat.

\section{Gene ontology}

Relative to $\mathbf{5 0 0 0}$

Relative to genome

$\quad$ Gene ontology
Response to other organism
Response to ethylene stimulus
Innate immune response
Response to wounding
Response to water deprivation
Jasmonic acid and ethylene-dependent systemic defence
response
Lipid metabolic process

$\begin{array}{llll}\text { Percentage } & \begin{array}{c}\text { GOstat p- } \\ \text { value }\end{array} & \text { Percentage } & \begin{array}{c}\text { GOstat p- } \\ \text { value }\end{array} \\ 45 & 0.00002 & 3 & 0.0008 \\ 25 & 0.006 & 2 & 0.05 \\ 25 & 0.01 & 2 & 0.02 \\ 18 & 0.01 & 1 & 0.05 \\ 14 & 0.04 & 1 & 0.002 \\ 50 & 0.001 & 1 & 0.03 \\ 25 & 0.05 & 5 & 0.02\end{array}$

Consistent with the GOstat analysis, some markers associated with the JA/ET responses such as the pathogenesis-related protein genes $P R-3$ and $P R-4$ (Samac et al. 1990; Potter et al. 1993) were induced at both time-points after $R$. solanacearum infection and confirmed by RT-qPCR (Fig. 3a; Table S1). A marker of the SA signalling pathway (PR-5) was not differentially expressed during early wilt but was repressed during late wilt (Table S1). $P R-1$, another marker of the SA response pathway, was absent from the microarray. These data suggest that the JA/ET defence pathway may be induced and the SA defence pathway may be repressed by the infection.

In addition to $P R-3$ and $P R-4$, RT-qPCR was carried out on a selection of genes (seed imbibition protein homologue - Sip1, Tyrosine amino transferase - TAT, oxygen evolving complex $23-O E C 23$ ) that showed significant differential expression at both wilt stages $(p<0.03)$ by microarray analysis. The independent RT-qPCR technique showed the same expression profiles, thus validating the microarray data (Figs $3 a, b)$.

Several water deprivation genes were induced during bacterial wilt infection in Col-5 plants. These include those encoding dehydrin family proteins: response to dehydration 17 ( $\mathrm{rd} 17)$ and rd19 (At1g20440 and At4g39090), cold-regulated genes COR78 and COR413 (At5g52310 and At2g15970), late embryogenic abundant protein 5 (At4g02380) and a NAC transcription factor (At1g52890). A protease inhibitor, named Arabidopsis thaliana drought repressive 4 (ATDR4; At1g73330) was repressed during both wilt stages. According to GENEVESTIGATOR, transcripts of ATDR4 decline to below detection levels in response to progressive drought stress. Responses similar to water deprivation would be expected for plants undergoing wilting due to $R$. solanacearum infection. During $R$. solanacearum infection, the xylem of the plant becomes clogged with bacteria and bacterial debris, which reduces the plant's ability to take up water and thus wilting ensues (Genin and Boucher 2002b). Thus, wilt disease would result from water deprivation, as well as from the biotic stress in the form of $R$. solanacearum infection which secretes cell wall degrading enzymes and effectors directly into the plant cell (reviewed in Hikichi et al. 2007). 

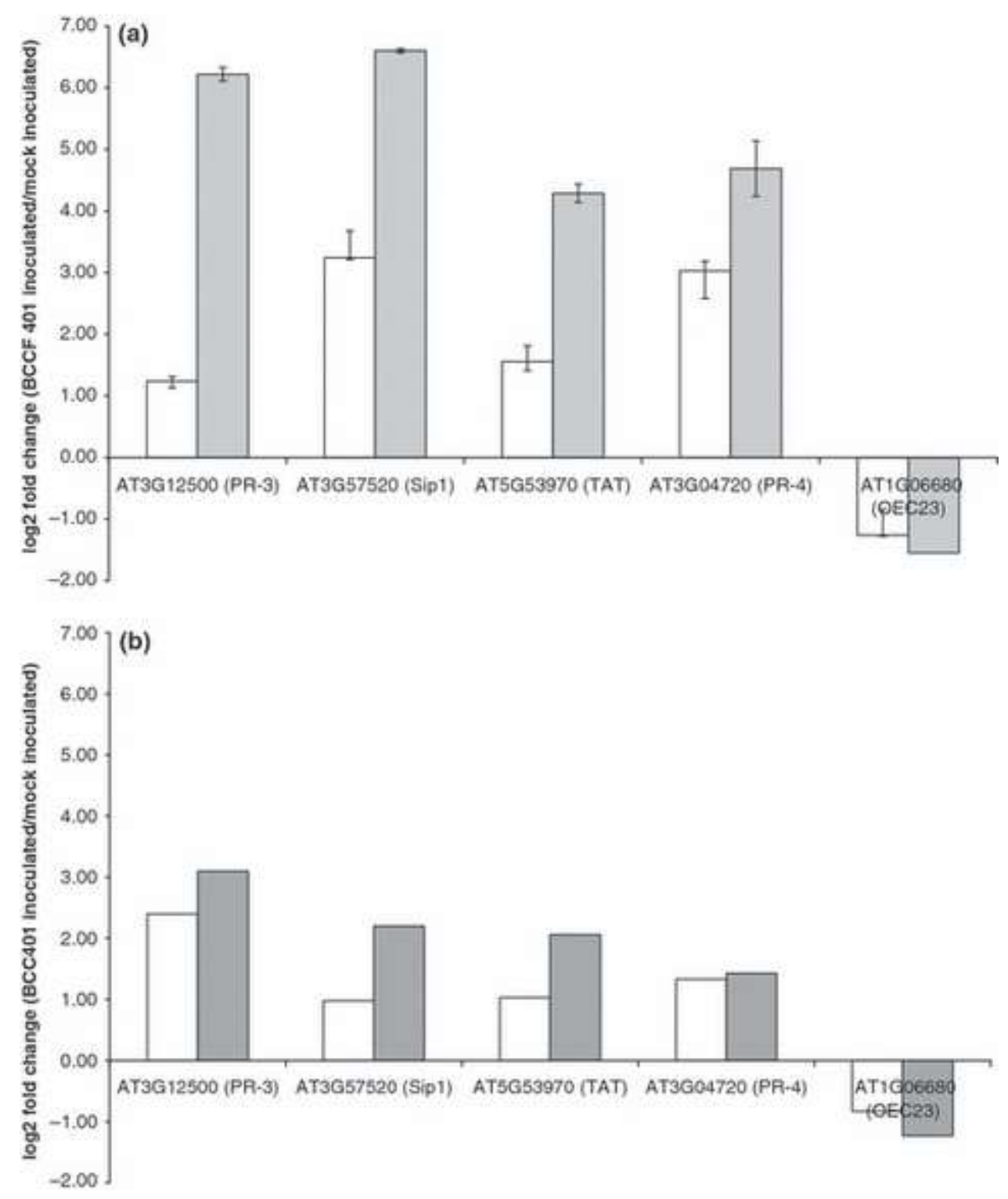

Figure 3. Expression data for selected Arabidopsis thaliana genes after Ralstonia solanacearum BCCF 401 inoculation relative to mock-inoculations at the same time-points. (a) RT-qPCR results and (b) microarray results. Gene expression ratios for the up-regulated genes basic endochitinase (PR-3), seed imbibition protein homologue (Sip1), tyrosine amino transferase (TAT) and pre-hevein like protein (PR-4) and for the downregulated gene oxygen evolving complex 23 (OEC23) are shown. Empty bars represent expression levels during early wilt infection stages while grey bars represent expression levels during late-wilt infection stages. In the case of RT-qPCR experiments, the data from at least three technical replicates are indicated. Results from a second biological replicate experiment were similar. The mean expression ratios of the five genes from the replicate microarray experiments are represented in (b).

\subsection{Evidence for manipulation of host defence responses by $R$. solanacearum from Eucalyptus}

Basal defences are often induced in the late stages of compatible interactions. These defences may be described as a weak form of immunity, ineffective in preventing disease (Jones and Dangl 2006). We investigated basal responses by performing bioinformatics comparisons to PAMP-induced responses in Col-0 treated with flg22 and LPS from Pst DC3000 (NASCARRAYS-121), and with Pst hrp ${ }^{-}$and Pst DC3000 (NASCARRAYS-120) for the 
134 genes shown to be differentially regulated during $R$. solanacearum infection. Data were available for 120 of these genes. A subset (38) of the 120 genes met the criteria of basal defence response genes as being induced/repressed by PAMPs and/or virulent pathogens, and were clustered into groups I-VI (Fig. 4).

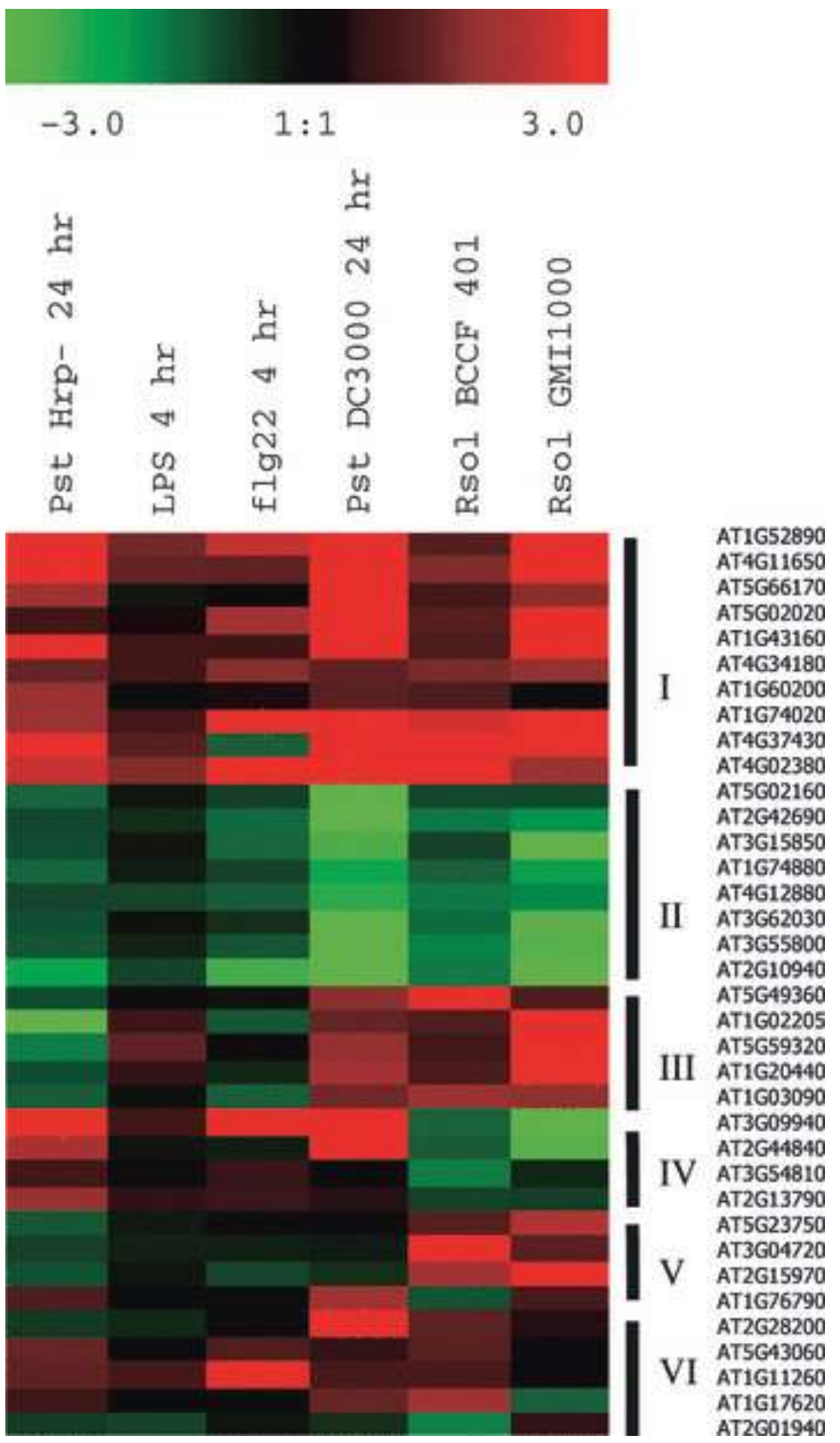

Figure 4. Heat map of Arabidopsis thaliana genes showing basal defence response profiles against R. solanacearum, Pst DC3000 and PAMPs. Green, black and red indicate down-regulated, unchanged and upregulated genes respectively. Cluster I are genes induced by PAMPs and effectors, cluster II are genes which are repressed by PAMPs and effectors, cluster III are genes which are repressed by PAMPs but induced by effectors, cluster IV are genes which are induced by PAMPs but repressed by $R$. solanacearum effectors, cluster $\mathrm{V}$ are genes that are repressed by PAMPs but induced by $R$. solanacearum effectors and cluster VI are genes which are repressed or induced by $R$. solanacearum GMI1000-specific effectors. Expression data was obtained from NASCArrays and this study.

Some basal defences were induced by BCCF401 infection since some of the 38 genes are also induced under conditions where basal defence are known to operate, e.g. during flg22 
and LPS treatment, Pst hrp ${ }^{-}$infection, and Pst DC3000 infection (Fig. 4 cluster I). This can be considered a weak form of PAMP Triggered Immunity or PTI (Jones and Dangl 2006) (Fig. 4 cluster I). Similarly, those genes that are repressed during $R$. solanacearum infection (GMI1000 and BCCF401), during Pst DC3000 infection as well as by PAMPs (flg22, LPS, hrp ${ }^{-}$), would be indicative of PTI against $R$. solanacearum (Fig. 4 cluster II). Cluster I contains genes such as LTP3 (AT4G02380), glycosyl hydrolase family protein 51 (AT4G34180) and cytochrome P450 81F1 (AT4G37430). Cluster II contains genes involved in photosynthesis such as plastocyanin-like domain-containing protein (AT2G42690), ribulose bisphosphate carboxylase small chain 3B (AT4G12880), and two kinases: Leucine-rich repeat family protein/protein kinase family protein (AT3G15850) and putative mitogen-activated protein kinase (MPK3) (AT3G55800).

Cluster III (Fig. 4) represents genes that could be targeted by effectors from Pst DC3000 or $R$. solanacearum that change the expression pattern mediated by PAMPs ( $h r p^{-}$treatment, and/or flg22). Such effectors could be common to both types of pathogen or distinct effectors which target the same protein. Genes in cluster IV (Fig. 4) can be considered specific $R$. solanacearum effector targets as they are induced during Pst hrp $^{-}$infection (i.e. they are PAMP-induced genes) and are also induced during Pst DC3000 infection, but are repressed during $R$. solanacearum GMI1000 and BCCF401 infection. Defence-related genes such as PR-3 (AT5G49360; cluster III) are possibly targets that are induced by bacterial effectors, while $P R-5$ is potentially down-regulated by $R$. solanacearum effectors (AT2G44840; cluster IV). Cluster V represents genes that may be responding to $R$. solanacearum effectors. Cluster VI represents genes that are induced by either PAMPs and Pst DC3000 or R. solanacearum BCCF401 but repressed by GMI1000. Cluster VI also contains genes that are repressed by PAMPs, Pst DC3000 and $R$. solanacearum BCCF401 but induced by GMI1000. Cluster VI may represent responses that are specific to GMI1000.

\section{Discussion}

\subsection{Arabidopsis thaliana ecotype Col-5 is susceptible to isolate BCCF401 from Eucalyptus}

We investigated the susceptibility of Arabidopsis thaliana to a Eucalyptus isolate of $R$. solanacearum and demonstrated that the model plant acted as a host for the forest pathogen. Arabidopsis has been adopted as a model plant for plant pathogen studies as pathogens from several plant species have been shown to be pathogenic on Arabidopsis (Glazebrook 2005); however, to our knowledge this is the first report of a forest tree pathogen which has been used to infect Arabidopsis. This pathosystem provides an opportunity to exploit the genetic resourses available for Arabidopsis to understand the response of the host Eucalyptus to $R$. solanacearum. Based on this pathosystem, the plant defence responses against $R$. solanacearum were investigated using microarray expression profiling of 5000 unigenes. We identified 141 genes that were significantly differentially regulated at early and/or late wilt, with 33 genes differentially regulated at both time-points (Fig. 2). Six genes were differentially regulated only during early wilt, whereas 102 genes were differentially regulated at late wilt, indicating that the bulk of gene expression changes occurred during late wilt (Fig. 2). 


\subsection{Signalling pathways in response to $R$. solanacearum BCCF401 infection}

The induction of the marker genes for the JA/ET signalling pathway, $P R-3$ and $P R-4$ by $R$. solanacearum was detected by microarray analysis and RT-qPCR (Fig. 3 ). This is in accordance with Hirsch et al. (2002) who observed an induction of these marker genes ( $P R-3$ and $P R-4)$ in response to $R$. solanacearum strain GMI1000 infection in leaves of the susceptible ecotype Col-0. Wilt symptoms were delayed in ethylene insensitive mutants in response to virulent strains of $R$. solanacearum (Hirsch et al. 2002). Ethylene was suggested to be involved in the wilting response and not $R$. solanacearum resistance as homozygous ein2-1 plants in a resistant background ( $\mathrm{Nd} 1$ ) remained resistant to a virulent R. solanacearum strain (Hirsch et al. 2002). Ralstonia solanacearum is also capable of producing plant-like hormones such as ethylene (Freebain and Buddenhagen 1964). This may be a strategy by the pathogen to promote disease as in the case of the bacterial toxin coronatine from $P$. syringae, which is a mimic of the hosts' jasmonate-isoleucine conjugate involved in defence signalling (Grant and Jones 2009). The JA signalling pathway antagonises the SA pathway, which is important for defence against $P$. syringae. The fact that there is coordinated expression of type three effectors and ethylene biosynthesis and that the levels of bacterial ethylene production causes the induction of plant ethylene marker genes increases the possibility that $R$. solanacearum may manipulate the plant ethylene signalling response to enhance susceptibility (Valls et al. 2006). Cluster V of Fig. 4 also indicates that $P R-4$ (At3g04720) is induced by $R$. solanacearum effectors but is not induced by PAMPs, suggesting pathogen manipulation of signalling leads to induction of PR-4.

The SA marker gene PR-5 was repressed at late-wilt time points in Col-5 suggesting that this pathway may be repressed during a compatible interaction; however, Hirsch et al. (2002) demonstrated that the SA mutants cpr1 and cpr5, which show constitutively elevated levels of SA and PR gene expression, and NahG transgenic plants, which had depleted endogenous $\mathrm{SA}$, were as susceptible to $R$. solanacearum GMI1000 as wild-type plants. The hypothesis that SA does play a limited role in plant defence against $R$. solanacearum is supported by Deslandes et al. (2002) who observed susceptibility to the pathogen in Nd1 plants homozygous for NahG. In Eucalyptus urophylla seedlings, the application of exogenous SA as a soil drench induced resistance against $R$. solanacearum, supporting a role for this signalling hormone in its natural host (Ran et al. 2005a).

Based on the RCC results in Table 1, it can be predicted that the ABA signalling pathway is operating in response to $R$. solanacearum infection. This observation is supported by $\mathrm{Hu}$ et al. (2008) who showed that approximately $40 \%$ of the genes up-regulated during wilting caused by GMI1000 infection in susceptible Arabidopsis plants were involved in ABA biosynthesis and signalling. These results lead to the conclusion that $A B A$ may enhance susceptibility to $R$. solanacearum, particularly during wilting at the later stages of infection. However, this is in contrast to reports that ABA may also play a role in resistant interactions. The secondary cell wall mutants irx 1 (irregular xylem 1), irx3 and irx5, which carry a mutation in the AtCesA8, AtCesA7 and AtCeSA8 genes, respectively, confer enhanced resistance to $R$. solanacearum GMI1000 independently of SA, JA and ethylene (HernandezBlanco et al. 2007). Comparative transcript profiling of the former mutants showed the constitutive induction of $A B A$-responsive genes suggesting a role for $A B A$ signalling in conferring disease resistance against $R$. solanacearum. Furthermore, ABA mutants (abi1-1, 
abi2-1 and aba1-6) were more susceptible to the pathogen. We hypothesize that this conundrum may be explained by differences in timing, i.e. ABA signalling at early stages of infection leads to resistance, whereas an enhanced $A B A$ response at late stages of disease serves to enhance the wilting response, as is proposed for ethylene. Measurement of ABA levels during the time course of infection in different interactions may shed light on this question.

\subsection{Manipulation of defence responses by $R$. solanacearum BCCF401}

Basal defences are often not sufficient to protect plants from pathogens as effectors are able to directly suppress host responses (He et al. 2006; Truman et al. 2006). We identified several genes with an increased expression during $R$. solanacearum infection or Pst DC3000 infection compared with PAMP-induced responses by Pst hrp- and flg22 or LPS. This suggests that the genes are potential targets of specific $R$. solanacearum effectors, which manipulate genes at the transcript level repressing the plant defence system. The genes described in Fig. 4 are potential biotechnology targets, which if uncoupled from pathogen manipulation (i.e. by overexpression of genes in cluster IV; or repression of genes in cluster III/V), may enhance resistance against $R$. solanacearum. GMI1000 infection of Arabidopsis plants also revealed a high percentage of transcripts which were induced by flg22 (Hu et al. 2008), suggesting that basal defence responses are generally active against

R. solanacearum.

In cluster III (Fig. 4), the gene At5g49360 (beta-xylosidase 1) is up-regulated by bacterial effectors from Pst and $R$. solanacearum but is down-regulated by PAMPs. This may reflect efforts by the pathogen to promote host cell wall degradation and facilitate spread of the pathogen. The cell wall polysaccharide substrates of beta-xylosidase 1 are xylan, arabinan and arabinoxylan (Minic 2008).

Another noteworthy gene which appears to be manipulated by $R$. solanacearum effectors is At2g13790 (AtSERK4, Fig. 4 Cluster IV). AtSERK4 is the closest paralog of the Arabidopsis receptor like kinase BAK1 (He et al. 2007; Hernandez-Blanco et al. 2007). BAK1 is a signalling partner of the flagellin receptor FLS2 and is thought to be a shared signalling partner for other PAMPs besides flagellin (Shan et al. 2008). Effectors from Pst, AvrPto and AvrPtoB bind BAK1 and interfere with the association of FLS2 with BAK1 during infection and impede BAK1-dependent host immune responses (Shan et al. 2008). AvrPto and AvrPtoB are also able to interact with AtSERK4 (Shan et al. 2008). The down-regulation of AtSERK4 by $R$. solanacearum effectors may reflect attempts by the pathogen to suppress AtSERK4dependent defences. Interestingly, in a resistant interaction between $R$. solanacearum GMI1000 and Nd-1, the expression of AtSERK4 does not change (data not shown) suggesting that in a resistant interaction, the suppression by $R$. solanacearum effectors may be relieved.

In cluster $V$ of Fig. 4, up-regulation of a marker gene of the ethylene pathway ( $P R-4$; At3g04720) could represent pathogen manipulation at the level of phytohormones, because $R$. solanacearum is known to produce ethylene (Aldon et al. 2000). 
Ralstonia. solanacearum contains over 70 putative effectors (Cunnac et al. 2004a,b; Occhialini et al. 2005; Angot et al. 2006; Meyer et al. 2006). Ralstonia solanacearum Petunia strain UW551, which belongs to race 3, biovar 2 has only 6 or 7 effectors 'missing' compared to GMI1000, and three effectors: RRSL00326, RRSL01019, and RRSL03923, are unique to UW551 (Mukaihara et al. 2004; Gabriel et al. 2006; Adie et al. 2007). BCCF401 belongs to the same race and biovar as GMI1000 (race 1, biovar 3), thus the two pathogens may share common effectors. Thus, it is intriguing as to why the two $R$. solanacearum strains GMI1000 and BCCF401 induce different expression profiles of some genes in Col-5, e.g. in cluster VI of Fig. 4, At2g01940 (shoot gravitropism 5) appears to be manipulated specifically by $R$. solanacearum GMI1000 effectors. The gene is also moderately induced in a resistant interaction between $R$. solanacearum GMI1000 and Arabidopsis ecotype Nd1 (data not shown). Shoot gravitropism 5 has transcription factor activity and mutant plants showed abnormal gravitropic response in inflorescence stems, while gravitropism in hypocotyls and roots remained unaltered (Morita et al. 2006). The role of this gene in defence against $R$. solanacearum is unknown and due to the fact that it is uniquely regulated by $R$. solanacearum GMI1000 makes it an attractive target for gene function studies.

Experiments are underway to determine the significance of some of the putative effector target genes using T-DNA knockout lines in Col-0. However, a single knock-out in the host may not reveal the desired phenotype as demonstrated by Hu et al. (2008) who screened 45 null mutants and found only two which showed a delay in wilt symptom development after challenge by $R$. solanacearum GMI1000 suggesting that effectors have multiple host targets to effect disease.

The availability of the genome sequence of Eucalyptus grandis in 2010 (Myburg et al. 2008) will provide a resource to design Eucalyptus-specific primers to target the Eucalyptus orthologs of host genes identified in this study. It would be of interest to determine whether the same signalling pathways are induced by the pathogen and whether the same targets are being manipulated in Eucalyptus. These results will strengthen the motivation for using Arabidopsis as a model for tree pathogens and allow for the identification of candidate genes which may be targeted to improve defence against $R$. solanacearum.

\section{Acknowledgements}

We thank the Agropolis Advanced Research Platform, Montpellier, France, the CNRS-South Africa bilateral research agreement and the National Research Foundation, South Africa for funding.

\section{References}

Adie, B. A.; Perez-Perez, J.; Perez-Perez, M. M.; Godoy, M.; Sanchez-Serrano, J. J.; Schmelz, E. A.; Solano, R., 2007: ABA is an essential signal for plant resistance to pathogens affecting JA biosynthesis and the activation of defenses in Arabidopsis. Plant Cell 19, 1665-1681.

Aldon, D.; Brito, B.; Boucher, C.; Genin, S., 2000: A bacterial sensor of plant cell contact controls the transcriptional induction of Ralstonia solanacearum pathogenicity genes. EMBO J. 19, 2304-2314. 
Angot, A.; Peeters, N.; Lechner, E.; Vailleau, F.; Baud, C.; Gentzbittel, L.; Sartorel, E.; Genschik, P.; Boucher, C.; Genin, S., 2006: Ralstonia solanacearum requires F-box-like domain-containing type III effectors to promote disease on several host plants. Proc. NatI Acad. Sci. U.S.A. 103, 14620-14625.

Arlat, M.; Gough, C. L.; Zischek, C.; Barberis, P. A.; Trigalet, A.; Boucher, C. A., 1992: Transcriptional organization and expression of the large hrp gene cluster of Pseudomonas solanacearum. Mol. Plant Microbe Interact. 5, 187-193.

Beißbarth, T.; Speed, T. P., 2004: GOstat: find statistically overrepresented gene ontologies within a group of genes. Bioinformatics 20, 1464-1465.

Boucher, C. A.; Barberis, P.; Trigalet, A. P.; Demery, D. A., 1985: Transposon mutagenesis of Pseudomonas solanacearum: isolation of Tn5-induced avirulent mutants. J. Gen. Microbiol. 131, 2449-2457.

Cao, P. J.; Bartley, L. E.; Jung, K. H.; Ronald, P. C., 2008: Construction of a rice glycosyltransferase phylogenomic database and identification of rice-diverged glycosyltransferases. Mol. Plant 1, 858.

Coutinho, T. A.; Roux, J.; Riedel, K. H.; Terblanche, J.; Wingfield, M. J., 2000: First report of bacterial wilt caused by Ralstonia solanacearum on eucalypts in South Africa. For. Pathol. 30, 205-210.

Cunnac, S.; Boucher, C.; Genin, S., 2004a: Characterization of the cis-acting regulatory element controlling HrpB-mediated activation of the type III secretion system and effector genes in Ralstonia solanacearum. J. Bacteriol. 186, 2309-2318.

Cunnac, S.; Occhialini, A.; Barberis, P.; Boucher, C.; Genin, S., 2004b: Inventory and functional analysis of the large Hrp regulon in Ralstonia solanacearum: identification of novel effector proteins translocated to plant host cells through the type III secretion system. Mol. Microbiol. 53, 115-128.

Dardick, C.; Ronald, P., 2006: Plant and animal pathogen recognition receptors signal through non-RD kinases. PLoS Pathog. 2, e2.

Debroy, S.; Thilmony, R.; Kwack, Y. B.; Nomura, K.; He, S. Y., 2004: A family of conserved bacterial effectors inhibits salicylic acid-mediated basal immunity and promotes disease necrosis in plants. Proc. Natl Acad. Sci. U.S.A. 101, 9927-9932.

Deslandes, L.; Pileur, F.; Liaubet, L.; Camut, S.; Can, C.; Williams, K.; Holub, E.; Beynon, J.; Arlat, M.; Marco, Y., 1998: Genetic characterization of RRS1, a recessive locus in Arabidopsis thaliana that confers resistance to the bacterial soilborne pathogen Ralstonia solanacearum. Mol. Plant Microbe Interact. 11, 659-667.

Deslandes, L.; Olivier, J.; Theulieres, F.; Hirsch, J.; Feng, D. X.; Bittner-Eddy, P.; Beynon, J.; Marco, Y., 2002: Resistance to Ralstonia solanacearum in Arabidopsis thaliana is conferred 
by the recessive RRS1-R gene, a member of a novel family of resistance genes. Proc. Natl Acad. Sci. U.S.A. 99, 2404-2409.

Felix, G.; Duran, J. D.; Volko, S.; Boller, T., 1999: Plants have a sensitive perception system for the most conserved domain of bacterial flagellin. Plant J. 18, 265-276.

Fouché-Weich, J.; Poussier, S.; Trigalet Demery, D.; Berger, D.; Coutinho, T., 2006: Molecular identification of some African strains of Ralstonia solanacearum from eucalypt and potato. J. Gen. Plant Pathol. 72, 369-373.

Freebain, H. T.; Buddenhagen, I. W., 1964: Ethylene production by Pseudomonas solanacearum. Nature 202, 313-314.

Gabriel, D. W.; Allen, C.; Schell, M.; Denny, T. P.; Greenberg, J. T.; Duan, Y. P.; Flores-Cruz, Z.; Huang, Q.; Clifford, J. M.; Presting, G.; Gonzalez, E. T.; Reddy, J.; Elphinstone, J.; Swanson, J.; Yao, J.; Mulholland, V.; Liu, L.; Farmerie, W.; Patnaikuni, M.; Balogh, B.; Norman, D.; Alvarez, A.; Castillo, J. A.; Jones, J.; Saddler, G.; Walunas, T.; Zhukov, A.; Mikhailova, N., 2006: Identification of open reading frames unique to a select agent: Ralstonia solanacearum race 3 biovar 2. Mol. Plant Microbe Interact. 19, 69-79.

Genin, S.; Boucher, C., 2002b: Ralstonia solanacearum: secrets of a major pathogen unveiled by analysis of its genome. Mol. Plant Pathol. 3, 111-118.

Glazebrook, J., 2005: Contrasting mechanisms of defense against biotrophic and necrotrophic pathogens. Ann. Rev. Phytopathol. 43, 205-227.

Grant, M. R.; Jones, J. D., 2009: Hormone (dis)harmony moulds plant health and disease. Science 324, 750-752.

He, P.; Shan, L.; Lin, N. C.; Martin, G. B.; Kemmerling, B.; Nurnberger, T.; Sheen, J., 2006: Specific bacterial suppressors of MAMP signaling upstream of MAPKKK in Arabidopsis innate immunity. Cell 125, 563-575.

He, K.; Gou, X.; Yuan, T.; Lin, H.; Asami, T.; Yoshida, S.; Russell, S. D.; Li, J., 2007: BAK1 and BKK1 regulate brassinosteroid-dependent growth and brassinosteroid-independent celldeath pathways. Curr. Biol. 17, 1109-1115.

Hernandez-Blanco, C.; Feng, D. X.; Hu, J.; Sanchez-Vallet, A.; Deslandes, L.; Llorente, F.; Berrocal-Lobo, M.; Keller, H.; Barlet, X.; Sanchez-Rodriguez, C.; Anderson, L. K.; Somerville, S.; Marco, Y.; Molina, A., 2007: Impairment of cellulose synthases required for Arabidopsis secondary cell wall formation enhances disease resistance. Plant Cell 19, 890-903.

Hikichi, Y.; Yoshimochi, T.; Tsujimoto, S.; Shinohara, R.; Nakaho, K.; Kanda, A.; Kiba, A.; Ohnishi, K., 2007: Global regulation of pathogenicity mechanism of Ralstonia solanacearum. Plant Biotech. 24, 149-154. 
Hirsch, J.; Deslandes, L.; Feng, D. X.; Balague, C.; Marco, Y., 2002: Delayed symptom development in ein2-1, an Arabidopsis ethylene-insensitive mutant, in response to bacterial wilt caused by Ralstonia solanacearum. Phytopathology 92, 1142-1148.

Hu, J.; Barlet, X.; Deslandes, L.; Hirsch, J.; Feng, D. X.; Somssich, I.; Marco, Y., 2008:

Transcriptional responses of Arabidopsis thaliana during wilt disease caused by the soilborne phytopathogenic bacterium, Ralstonia solanacearum. PLoS ONE 3, e2589.

Jones, J. D.; Dangl, J. L., 2006: The plant immune system. Nature 444, 323-329.

Law, P. J.; Claudel-Renard, C.; Joubert, F.; Louw, A. I.; Berger, D. K., 2008: MADIBA: a web server toolkit for biological interpretation of plasmodium and plant gene clusters. $B M C$ Genomics 9, 105-116.

Maniatis, T.; Fritsch, E. F.; Sambrook, J., 1982: Molecular Cloning. New York: Cold Spring Harbor Laboratory, Cold Spring Harbor.

Meyer, A.; Puhler, A.; Niehaus, K., 2001: The lipopolysaccharides of the phytopathogen Xanthomonas campestris pv. campestris induce an oxidative burst reaction in cell cultures of Nicotiana tabacum. Planta 213, 214-222.

Meyer, D.; Cunnac, S.; Gueneron, M.; Declercq, C.; Van Gijsegem, F.; Lauber, E.; Boucher, C.; Arlat, M., 2006: PopF1 and PopF2, two proteins secreted by the type III protein secretion system of Ralstonia solanacearum, are translocators belonging to the HrpF/NopX family. J. Bacteriol. 188, 4903-4917.

Minic, Z., 2008: Physiological roles of plant glycoside hydrolases. Planta 227, 723-740.

Morita, M. T.; Sakaguchi, K.; Kiyose, S.; Taira, K.; Kato, T.; Nakamura, M.; Tasaka, M., 2006: A $\mathrm{C} 2 \mathrm{H} 2$-type zinc finger protein, SGR5, is involved in early events of gravitropism in Arabidopsis inflorescence stems. Plant J. 47, 619-628.

Mukaihara, T.; Tamura, N.; Murata, Y.; Iwabuchi, M., 2004: Genetic screening of Hrp type IIIrelated pathogenicity genes controlled by the HrpB transcriptional activator in Ralstonia solanacearum. Mol. Microbiol. 54, 863-875.

Murashige, T.; Skoog, F., 1962: A revised medium for rapid growth and bio assays with tobacco tissue cultures. Physiol. Plant. 15, 473-497.

Myburg, A. A.; Grattapaglia, D.; Tuskan, G. A.; Schmutz, J.; Barry, K.; Bristow, J., 2008: The Eucalyptus Genome Network. Sequencing the Eucalyptus Genome: Genomic Resources for Renewable Energy and Fiber Production. Plant \& Animal Genome XVI Conference. Abstract W195, San Diego, CA.

Naidoo, S.; Murray, S.; Denby, K.; Berger, D., 2007: Microarray analysis of the Arabidopsis thaliana cir 1(constitutively induced resistance 1 ) mutant reveals candidate defence response genes against Pseudomonas syringae pv tomato DC 3000. S. Afr. J. Bot. 73, 412421. 
Newman, M.; Roepenack, E. V.; Daniels, M.; Dow, M., 2000: Lipopolysaccharides and plant responses to phytopathogenic bacteria. Mol. Plant Pathol. 1, 25-31.

Occhialini, A.; Cunnac, S.; Reymond, N.; Genin, S.; Boucher, C., 2005: Genome-wide analysis of gene expression in Ralstonia solanacearum reveals that the hrpB gene acts as a regulatory switch controlling multiple virulence pathways. Mol. Plant Microbe Interact. 18, 938-949.

Pfund, C.; Tans-Kersten, J.; Dunning, F. M.; Alonso, J. M.; Ecker, J. R.; Allen, C.; Bent, A. F., 2004: Flagellin is not a major defense elicitor in Ralstonia solanacearum cells or extracts applied to Arabidopsis thaliana. Mol. Plant Microbe Interact. 17, 696-706.

Potter, S.; Uknes, S.; Lawton, K.; Winter, A. M.; Chandler, D.; Dimaio, J.; Novitzky, R.; Ward, E.; Ryals, J., 1993: Regulation of a hevein-like gene in Arabidopsis. Mol. Plant Microbe Interact. 6, 680-685.

Poueymiro, M.; Genin, S., 2009: Secreted proteins from Ralstonia solanacearum: a hundred tricks to kill a plant. Curr. Opin. Microbiol. 12, 44-52.

Ran, L. X.; Li, Z. N.; Wu, G. J.; Van Loon, L. C.; Bakker, P., 2005a: Induction of systemic resistance against bacterial wilt in Eucalyptus urophylla by fluorescent Pseudomonas spp. Eur. J. Plant Pathol. 113, 59-70.

Ran, L.; Liu, C.; Wu, G.; Van Loon, L.; Bakker, P., 2005b: Suppression of bacterial wilt in Eucalyptus urophylla by fluorescent Pseudomonas spp. in China. Biol. Control 32, 111-120.

Roux, J.; Coutinho, T. A.; Wingfield, M. J.; Byabashaija, D. M., 2001: Diseases of plantation Eucalyptus in Uganda. S. Afr. J. Sci. 97, 16-18.

Saeed, A. I.; Sharov, V.; White, J.; Li, J.; Liang, W.; Bhagabati, N.; Braisted, J.; Klapa, M.; Currier, T.; Thiagarajan, M.; Sturn, A.; Snuffin, M.; Rezantsev, A.; Popov, D.; Ryltsov, A.; Kostukovich, E.; Borisovsky, I.; Liu, Z.; Vinsavich, A.; Trush, V.; Quackenbush, J., 2003: TM4: a free, open-source system for microarray data management and analysis. BioTechniques 34 , 374-378.

Salanoubat, M.; Genin, S.; Artiguenave, F.; Gouzy, J.; Mangenot, S.; Arlat, M.; Billault, A.; Brottier, P.; Camus, J. C.; Cattolico, L.; Chandler, M.; Choisne, N.; Claudel-Renard, C.; Cunnac, S.; Demange, N.; Gaspin, C.; Lavie, M.; Moisan, A.; Robert, C.; Saurin, W.; Schiex, T.; Siguier, P.; Thebault, P.; Whalen, M.; Wincker, P.; Levy, M.; Weissenbach, J.; Boucher, C. A., 2002: Genome sequence of the plant pathogen Ralstonia solanacearum. Nature 415, 497-502.

Samac, D. A.; Hironaka, C. M.; Yallaly, P. E.; Shah, D. M., 1990: Isolation and characterization of the genes encoding basic and acidic chitinase in Arabidopsis thaliana. Plant Physiol. 93, 907-914.

Shan, L.; He, P.; Li, J.; Heese, A.; Peck, S. C.; Nurnberger, T.; Martin, G. B.; Sheen, J., 2008: Bacterial effectors target the common signaling partner BAK1 to disrupt multiple MAMP receptor-signaling complexes and impede plant immunity. Cell Host Microbe 4, 17-27. 
Tao, Y.; Xie, Z.; Chen, W.; Glazebrook, J.; Chang, H. S.; Han, B.; Zhu, T.; Zou, G.; Katagiri, F., 2003: Quantitative nature of Arabidopsis responses during compatible and incompatible interactions with the bacterial pathogen Pseudomonas syringae. Plant Cell 15, 317-330.

Thatcher, L. F.; Anderson, J. P.; Singh, K. B., 2005: Plant defense responses: what have we learnt from Arabidopsis? Functional Plant Biol. 32, 1-19.

Thilmony, R.; Underwood, W.; He, S. Y., 2006: Genome-wide transcriptional analysis of the Arabidopsis thaliana interaction with the plant pathogen Pseudomonas syringae pv. tomato DC3000 and the human pathogen Escherichia coli 0157:H7. Plant J. 46, 34-53.

Thomma, B. P.; Eggermont, K.; Tierens, K. F.; Broekaert, W. F., 1999: Requirement of functional ethylene-insensitive 2 gene for efficient resistance of Arabidopsis to infection by Botrytis cinerea. Plant Physiol. 121, 1093-1102.

Truman, W.; De Zabala, M. T.; Grant, M., 2006: Type III effectors orchestrate a complex interplay between transcriptional networks to modify basal defence responses during pathogenesis and resistance. Plant J. 46, 14-33.

Valls, M.; Genin, S.; Boucher, C., 2006: Integrated regulation of the type III secretion system and other virulence determinants in Ralstonia solanacearum. PLoS Pathog. 2, e82.

Vasse, J.; Genin, S.; Frey, P.; Boucher, C.; Brito, B., 2000: The hrpB and hrpG regulatory genes of Ralstonia solanacearum are required for different stages of the tomato root infection process. Mol. Plant Microbe Interact. 13, 259-267.

Winstead, N. N.; Kelman, A., 1952: Inoculation techniques for evaluating resistance to Pseudomonas solanacearum. Phytopathology 42, 628-634.

Wolfinger, R. D.; Gibson, G.; Wolfinger, E. D.; Bennett, L.; Hamadeh, H.; Bushel, P.; Afshari, C.; Paules, R. S., 2001: Assessing gene significance from cDNA microarray expression data via mixed models. J. Comput. Biol. 8, 625-637.

Wroblewski, T.; Caldwell, K. S.; Piskurewicz, U.; Cavanaugh, K. A.; Xu, H.; Kozik, A.; Ochoa, O.; Mchale, L. K.; Lahre, K.; Jelenska, J., 2009: Comparative large-scale analysis of interactions between several crop species and the effector repertoires from multiple pathovars of Pseudomonas and Ralstonia. Plant Physiol. 150, 1733.

Xu, J.; Pan, Z. C.; Prior, P.; Xu, J. S.; Zhang, Z.; Zhang, H.; Zhang, L. Q.; He, L. Y.; Feng, J., 2009: Genetic diversity of Ralstonia solanacearum strains from China. Eur. J. Plant Pathol. 125, 113.

Zeidler, D.; Zahringer, U.; Gerber, I.; Dubery, I.; Hartung, T.; Bors, W.; Hutzler, P.; Durner, J., 2004: Innate immunity in Arabidopsis thaliana: lipopolysaccharides activate nitric oxide synthase (NOS) and induce defense genes. Proc. Natl Acad. Sci. U.S.A. 101, 15811-15816.

Zimmermann, P.; Hennig, L.; Gruissem, W., 2005: Gene-expression analysis and network discovery using Genevestigator. Trends Plant Sci. 10, 407-409. 


\section{Supporting Information}
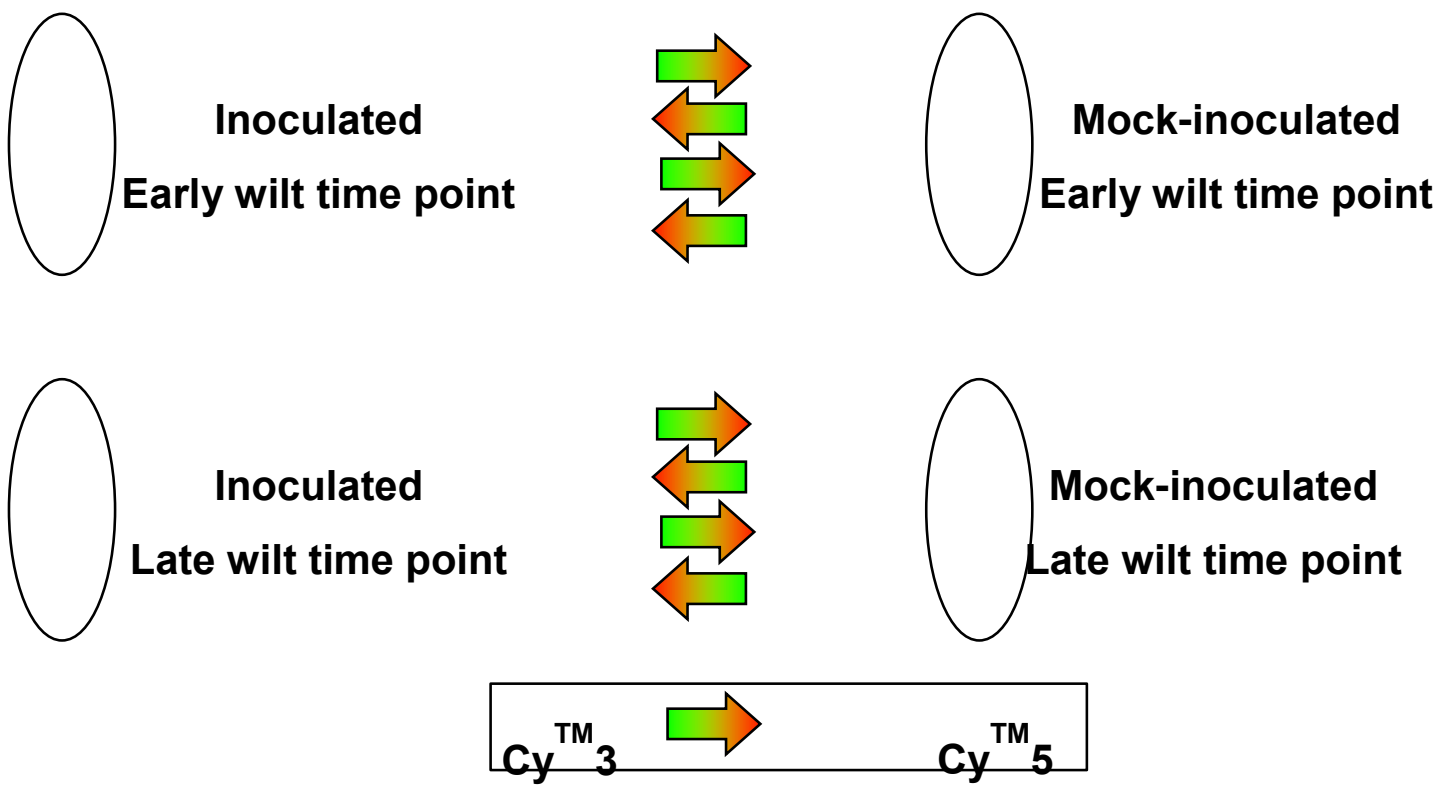

Supplementary Figure S1. Microarray experimental design used to compare expression patterns in Arabidopsis thaliana Col-5 plants inoculated with Ralstonia solanacearum BCCF401 and mock-inoculated plants during early wilt and late wilt stages. Ovals represent samples and arrows represent slides. The head of the arrow represents samples labelled with the $\mathrm{Cy}^{\mathrm{TM}} 5$ dye and the tail of the arrow represents samples labelled with the $\mathrm{Cy}^{\mathrm{TM}} 3$ dye. Arrows in opposite directions indicate a dye swap. The design includes biological replicates of each treatment.

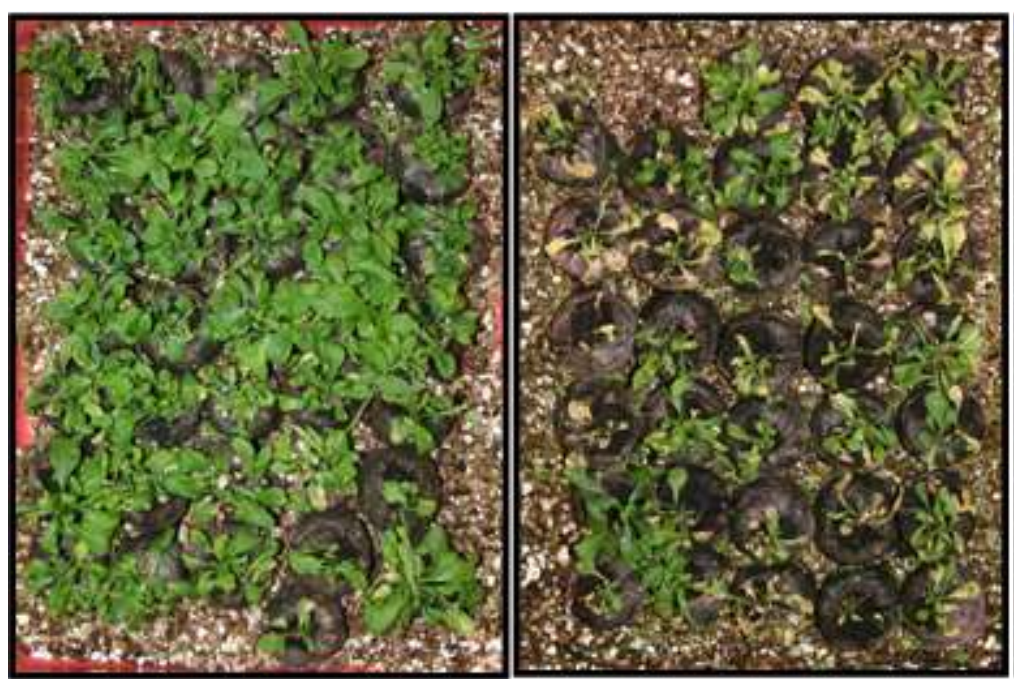

A

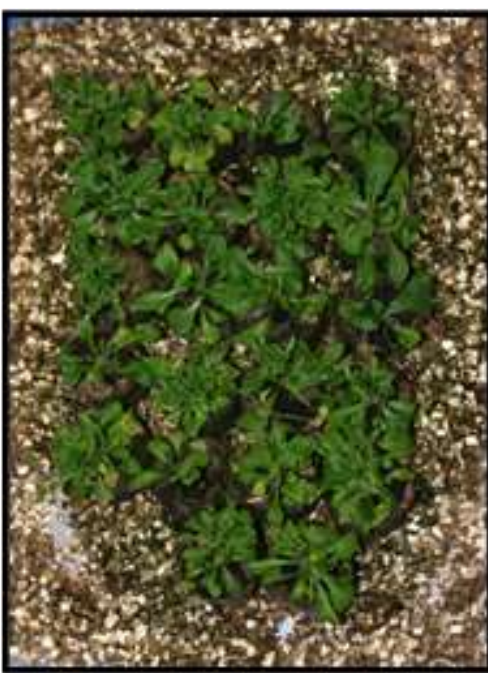

C

Supplementary Figure S2.Arabidopsis thaliana ecotypes inoculated with Ralstonia solanacearum BCCF401 at 21 days after inoculation. Ecotype Col-5 inoculated with the $h r p^{-}$mutant of isolate BCCF401 (A), ecotype Col-5 inoculated with BCCF401* (B) and ecotype Nd-1 inoculated with BCCF401* (C). 


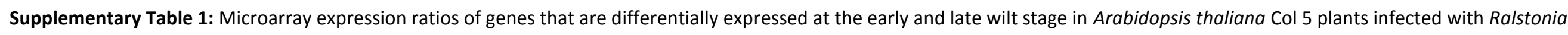
solanacearum BCCF401.

\section{TAIR Accession}

AT4G11650

AT5G59320

AT3G01420

AT3G12500

AT1G47830

AT4G16260

AT4G37430

AT3G28710

AT1G78890

AT1G32450

AT3G04720

AT1G31130

AT5G52310

AT4G13250

AT5G53970

AT3G57520

AT1G51670

AT5G11520

AT3G10630

AT1G06570

AT5G58500

AT2G42890

AT5G49360

AT4G39090

AT2G33150

\section{Description}

ATOSM34 (OSMOTIN 34)

LTP3 (LIPID TRANSFER PROTEIN 3); lipid binding

ALPHA-DOX1 (ALPHA-DIOXYGENASE 1)

ATHCHIB (BASIC CHITINASE); chitinase

clathrin coat assembly protein, putative

glycosyl hydrolase family 17 protein

CYP91A2 (CYTOCHROME P450 MONOOXYGENASE 91A2); oxygen binding

H+-transporting two-sector ATPase, putative

similar to Os08g0230000 [Oryza sativa (japonica cultivar-group)]

proton-dependent oligopeptide transport (POT) family protein

PR4 (PATHOGENESIS-RELATED 4)

similar to conserved hypothetical protein [Medicago truncatula] (GB:ABE90086.1)

COR78 (COLD REGULATED 78)

short-chain dehydrogenase/reductase (SDR) family protein

aminotransferase, putative

ATSIP2 (ARABIDOPSIS THALIANA SEED IMBIBITION 2)

contains domain Cysteine proteinases (SSF54001)

ASP3 (ASPARTATE AMINOTRANSFERASE 3)

glycosyl transferase family 1 protein

PDS1 (PHYTOENE DESATURATION 1)

similar to hypothetical protein [Oryza sativa (japonica cultivar-group)]

AML2; RNA binding

BXL1 (BETA-XYLOSIDASE 1); hydrolase, hydrolyzing O-glycosyl compounds

RD19 (RESPONSIVE TO DEHYDRATION 19); cysteine-type peptidase

PED1 (PEROXISOME DEFECTIVE 1)
EARLY WILT

$\log _{2}$ Fold Change

3.64

2.67

2.45

2.40

2.33

2.19

1.86

1.78

1.41

1.34

1.33

1.22

1.14

1.07

1.03

0.98

0.96

0.95

0.91

0.91

0.87

0.86

0.85

0.83

0.82

Negative $\log _{10}(p$ value)

2.72

1.75

5.55

2.47

2.04

6.59

1.92

2.05

1.75

1.80

7.26

3.75

1.58

1.72

2.52

2.12

2.31

1.67

2.46

2.66

4.39

2.20

5.05

10.43

2.24

\section{TAIR Accession}

AT3G22231

AT5G24770

AT1G73330

AT2G44840

AT4G15440

AT1G75040

AT1G14030

AT5G09810

\section{Description}

PCC1 (PATHOGEN AND CIRCADIAN CONTROLLED 1)

VSP2 (VEGETATIVE STORAGE PROTEIN 2); acid phosphatase

ATDR4 (Arabidopsis thaliana drought-repressed 4)

ATERF13/EREBP (ETHYLENE-RESPONSIVE ELEMENT BINDING FACTOR 13)

HPL1 (HYDROPEROXIDE LYASE 1)

PR5 (PATHOGENESIS-RELATED GENE 5)

RIBUSCO large subunit N-methyltransferase, putative

ACTIN 2

\section{$\log _{2}$ Fold Change}

$-1.81$

$-1.30$

$-1.17$

$-1.13$

$-1.11$

$-1.09$

$-1.02$

$-0.98$
EARLY WILT

Negative $\log _{10}(p$ value)

1.58

2.78

2.29

1.55

2.76

3.06

1.70 


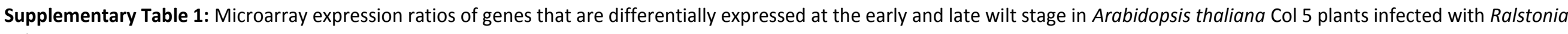
solanacearum BCCF401.

TAIR Accession

AT1G70410

AT1G04250

AT3G28300

AT3G14210

AT1G06680

AT5G61650 carbonic anhydrase, putative / carbonate dehydratase, putative

AXR3 (AUXIN RESISTANT 3); transcription factor

AT14A

ESM1 (EPITHIOSPECIFIER MODIFIER 1)

PSBP-1 (OXYGEN-EVOLVING ENHANCER PROTEIN 2)

CYCP4;2 (CYCLIN P4;2); cyclin-dependent protein kinase
EARLY WILT

$\log _{2}$ Fold Change

$\begin{array}{ll}-0.89 & 1.80 \\ -0.88 & 2.19 \\ -0.85 & 2.25 \\ -0.83 & 2.93 \\ -0.83 & 2.53 \\ -0.80 & 1.85\end{array}$

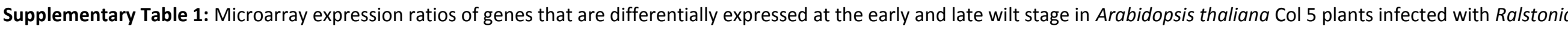
solanacearum BCCF401.

\begin{tabular}{|c|c|c|c|}
\hline \multirow[b]{2}{*}{ TAIR Accession } & \multirow[b]{2}{*}{ Description } & \multicolumn{2}{|c|}{ LATE WILT } \\
\hline & & log2 Fold Change & Negative $\log _{10}(p$ value $)$ \\
\hline AT3G01420 & pathogen-inducible alpha-dioxygenase (Nicotiana attenuata) & 4.49 & 7.91 \\
\hline AT4G11650 & Osmotin-like protein (OSM34) & 4.27 & 2.22 \\
\hline AT5G59320 & Lipid transfer protein 3 (LTP3) & 3.84 & 3.36 \\
\hline AT4G37430 & Cytochrome P450 81F1 (CYP81F1) & 3.60 & 3.08 \\
\hline AT2G47770 & Benzodiazepine receptor-related, contains weak similarity to Peripheral-type benzodiazepine receptor (PBR) & 3.57 & 2.35 \\
\hline AT3G12500 & Basic endochitinase, identical to basic endochitinase precursor SP:P19171 from (Arabidopsis thaliana) & 3.11 & 2.61 \\
\hline AT2G22470 & Arabinogalactan-protein (AGP2) & 3.08 & 2.69 \\
\hline AT1G03220 & Extracellular dermal glycoprotein, putative / EDGP & 2.55 & 3.05 \\
\hline AT5G11520 & Aspartate aminotransferase, chloroplast (YLS4) & 2.35 & 3.19 \\
\hline AT2G34500 & Cytochrome P450 family protein & 2.33 & 2.43 \\
\hline AT3G57520 & Alkaline alpha galactosidase, putative, similar to alkaline alpha galactosidase II (Cucumis melo) & 2.28 & 2.67 \\
\hline AT4G13250 & Short-chain dehydrogenase/reductase (SDR) family protein & 2.18 & 2.67 \\
\hline AT5G53970 & Encodes tyrosine aminotransferase which is strongly induced upon aging and coronatine treatment & 2.06 & 5.67 \\
\hline AT1G74020 & Strictosidine synthase family protein & 2.05 & 2.87 \\
\hline AT4G19920 & Disease resistance protein (TIR class), putative & 2.01 & 2.55 \\
\hline AT1G52890 & No apical meristem (NAM) family protein & 1.84 & 2.46 \\
\hline AT3G44880 & Rieske (2Fe-2S) domain-containing protein & 1.83 & 2.34 \\
\hline AT3G03470 & Cytochrome P450, putative & 1.81 & 9.42 \\
\hline AT2G33150 & Encodes a peroxisomal 3-ketoacyl-CoA thiolase & 1.79 & 3.20 \\
\hline AT1G11260 & Glucose transporter (STP1) & 1.77 & 2.27 \\
\hline AT1G43160 & Encodes a member of the ERF subfamily B-4 of ERF/AP2 transcription factor family (RAP2.6). & 1.69 & 3.35 \\
\hline AT5G66760 & Succinate dehydrogenase (ubiquinone) flavoprotein subunit & 1.67 & 2.75 \\
\hline
\end{tabular}




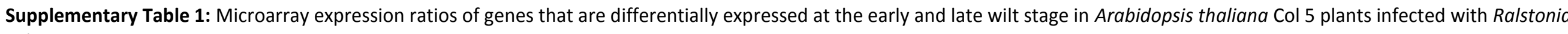
solanacearum BCCF401.

\section{TAIR Accession}

AT1G31130

AT5G66170

AT5G52310

AT1G78890

AT5G46180

AT5G06760

AT4G39090

AT5G49360

AT2G42890

AT3G45310

AT3G04720

AT3G10740

AT5G49360

AT3G02550

AT5G54080

AT4G34180

AT5G23750

AT1G03090

AT4G02380

AT1G06570

AT3G13450

AT5G13800

AT1G20440

AT3G22840

AT2G15970

AT5G13800

AT4G37390

AT3G11780

AT5G43060

AT4G15530

AT5G58500

AT5G42250

AT2G01340

AT2G28200

AT1G75170
Expressed protein

Senescence-associated family protein

Low-temperature-responsive protein 78 (LTI78) / desiccation-responsive protein 29A (RD29A)

Expressed protein

Ornithine aminotransferase, putative

Late embryogenesis abundant group 1 domain-containing protein / LEA group 1 domain-containing protein

Cysteine proteinase RD19a (RD19A) / thiol protease

Glycosyl hydrolase family 3 protein

RNA recognition motif (RRM)-containing protein

Cysteine proteinase, putative

Hevein-like protein (HEL)

Glycosyl hydrolase family protein 51

Glycosyl hydrolase family 3 protein

LOB domain protein 41 / lateral organ boundaries domain protein 41 (LBD41)

Homogentisate 1,2-dioxygenase / homogentisicase/homogentisate oxygenase / homogentisic acid oxidase (HGO

Cyclase family protein, contains Pfam profile: PF04199 putative cyclase

Remorin family protein

Methylcrotonyl-CoA carboxylase alpha chain, mitochondrial / 3-methylcrotonyl-CoA carboxylase 1 (MCCA)

Late embryogenesis abundant 3 family protein / LEA3 family protein

4-hydroxyphenylpyruvate dioxygenase (HPD)

2-oxoisovalerate dehydrogenase / 3-methyl-2-oxobutanoate dehydrogenase

Hydrolase, alpha/beta fold family protein, low similarity to hydrolase

Dehydrin (COR47), identical to dehydrin COR47

Chlorophyll A-B binding family protein / early light-induced protein (ELIP)

Cold-acclimation protein, putative (FL3-5A3)

Hydrolase, alpha/beta fold family protein, low similarity to hydrolase (Terrabacter sp. DBF63) GI:14196240

(1)

MD-2-related lipid recognition domain-containing protein

similar to cysteine proteinase RD21A precursor (thiol protease) GI:435619, SP:P43297 from (Arabidopsis thaliana)

Similar to pyruvate,orthophosphate dikinase [Flaveria brownii] (GB:CAA55784.1);

Expressed protein, contains Pfam profile PF04852

Alcohol dehydrogenase, putative, similar to alcohol dehydrogenase ADH GI:7705214 from (Lycopersicon esculentum);

Expressed protein

Similar to zinc finger (C2H2 type) family protein [Arabidopsis thaliana] (TAIR:At5g04390.1)

SEC14 cytosolic factor family protein / phosphoglyceride transfer family protein, similar to polyphosphoinositide binding protein Ssh1p (GI:2739044) \{Glycine max\}

LATE WILT

log2 Fold Change

1.56

1.53

1.51

1.50

1.50

1.50

1.48

1.47

1.47

1.43

1.43

1.42

136

1.31

1.28

1.24

1.23

1.21

1.20

1.19

1.18

1.18

1.16

1.16

1.15

1.15

1.14

1.14

1.14

1.13

1.12

1.10

1.10

1.09

1.09
Negative $\log _{10}$ ( $p$ value)

3.28

2.33

1.56

2.39

2.71

3.70

17.86

4.46

9.13

2.47

5.58

3.79

4.74

2.68

2.89

4.26

2.19

2.02

2.95

3.24

4.02

2.71

2.04

2.13

2.04

2.38

6.08

2.89

4.75

7.38

2.47

2.73

2.46

2.23 


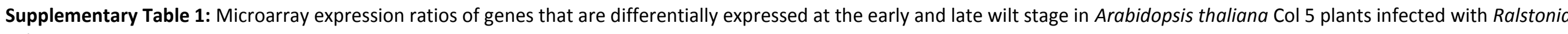
solanacearum BCCF401.

TAIR Accession Description

AT5G02020

AT3G50370

AT1G72770

AT3G48880

AT1G02205

AT5G45350

AT3G17780

AT3G28550

AT5G60580

AT5G27350

AT3G26100

AT3G58750

AT3G55610

AT5G21990

AT1G60200

AT1G17620

AT2G38710

\section{Expressed protein}

Expressed protein

Protein phosphatase $2 \mathrm{C} \mathrm{P} 2 \mathrm{C}-\mathrm{HA}$

F-box family protein, N7 protein - Medicago truncatula, EMBL:CAA768

CER1 protein, identical to maize gl1 homolog (glossy1 locus)

Proline-rich family protein

Expressed protein

Proline-rich extensin-like family protein

Zinc finger (C3HC4-type RING finger) family protein

Sugar-porter family protein 1 (SFP1)

Regulator of chromosome condensation (RCC1) family protein

Encodes a peroxisomal citrate synthase that is expressed throughout seedling and shoot development.

Delta 1-pyrroline-5-carboxylate synthetase B / P5CS B (P5CS2), identical to SP|P54888

Tetratricopeptide repeat (TPR)-containing protein, contains Pfam profile PF00515: TPR Domain

Splicing factor PWI domain-containing protein

Expressed protein

AMMECR1 family, similar to AMMECR1 (GI:6063688)
LATE WILT

Negative $\log _{10}(p$ value $)$

1.08

1.03

1.01

1.00

1.00

0.99

0.98

0.95

0.95

0.92

0.91

0.89

0.85

0.84

0.84

0.83

0.81

4.35

2.94

3.73

2.01

11.05

3.13

2.42

2.17

2.68

4.26

2.17

2.79

2.37

2.39

3.12

2.79

2.70

\section{TAIR Accession Description}

AT3G22231

AT3G54810

AT2G44840

AT5G52820

AT5G24770

AT3G13140

AT3G45640

AT3G15530

AT4G16670

AT1G14030

AT5G38410

AT5G02160

AT4G12880

AT4G11320

AT1G73330

AT4G15440
Encodes a member of a novel 6 member Arabidopsis gene family (PPC1)

Encodes a protein containing a GATA type zinc finger domain

Encodes a member of the ERF subfamily B-3 of ERF/AP2 transcription factor family.

WD-40 repeat family protein / notchless protein

Vegetative storage protein 2 (VSP2)

Hydroxyproline-rich glycoprotein family protein

Mitogen-activated protein kinase, putative / MAPK, putative (MPK3)

Expressed protein

Expressed protein

RIBUSCO large subunit N-methyltransferase, putative

RuBisCO small subunit 3B (RBCS-3B) (ATS3B),

Expressed protein

Plastocyanin-like domain-containing protein

Cysteine proteinase, putative, contains similarity to cysteine proteinase RD21A

Protease inhibitor, putative (DR4), identical to Dr4 Gl:469114 from (Arabidopsis thaliana);

member of the CYP74B cytochrome p450 family

\section{log2 Fold Change}

$-2.79$

$-2.41$

$-1.96$

$-1.68$

$-1.67$

$-1.60$

$-1.54$

$-1.51$

$-1.45$

$-1.43$

$-1.42$

$-1.42$

$-1.42$

$-1.37$

$-1.32$

$-1.28$
LATE WILT

Negative $\log _{10}(p$ value $)$

1.70

2.41

2.31

2.29

2.23

2.55

2.40

2.79

3.53

2.04

3.28

2.19

2.04

3.10

2.79 
Encodes the chloroplast enzyme sedoheptulose-1,7-bisphosphatase (SBPase)

Stress-inducible protein, putative, similar to sti (stress inducible protein) (Glycine max)

DNAJ heat shock N-terminal domain-containing protein (J20)

Photosystem II oxygen-evolving complex 23 (OEC23)

Fructose-bisphosphate aldolase, putative

AT4G38970

AT3G58760

Ankyrin protein kinase

AT3G09940

AT1G76790

AT3G15850

AT2G44210

AT1G69120

Monodehydroascorbate reductase, putative,

O-methyltransferase family 2 protein, similar to caffeic acid O-methyltransferase similar to delta 9 acyl-lipid desaturase (ADS1)

Expressed protein, Pfam profile PF03080: Arabidopsis proteins of unknown function

AT5G44340

AT1G55450

AT5G40950

AT2G01940

AT5G61650

AT1G75040

AT4G21720

AT1G74880

AT3G28300

AT2G05920

AT3G62030

AT4G23750

AT2G42690

AT1G65960

AT1G13260

AT3G27830

AT3G14210

AT3G16470

AT2G10940

AT1G03130

AT4G32260

AT4G24190

AT5G67290

AT4G01050

AT1G70410

AT1G12000

AT5G38420

beta tubulin

embryo-abundant protein-related, similar to embryo-abundant protein

50 S ribosomal protein $\mathrm{L} 27$

Similar to zinc finger ( $\mathrm{C} 2 \mathrm{H} 2$ type) family protein [Arabidopsis thaliana]

Cyclin family protein, similar to cyclin 2 (Trypanosoma brucei)

PR5 (PATHOGENESIS-RELATED GENE 5)

Expressed protein, (Arabidopsis thaliana)

Encodes subunit NDH-O of NAD(P)H:plastoquinone dehydrogenase complex ( $\mathrm{Ndh}$ complex)

Subtilase family protein, contains similarity to cucumisin-like serine protease

Peptidyl-prolyl cis-trans isomerase, chloroplast A-binding protein (ROC4)

Encodes a member of the ERF subfamily B-5 of ERF/AP2 transcription factor family

DNA-binding protein RAV1 (RAV1)

50 ribosomal protein L12-1, chloroplast (CL12-A)

Myrosinase-associated protein

Jacalin lectin family protein

Protease inhibitor/seed storage/lipid transfer protein (LTP) family protein

Photosystem I reaction center subunit II, chloroplast precursor

identical to cDNA chloroplast ATP synthase beta chain precursor (atpG) GI:5730140

Shepherd protein (SHD) / clavata formation protein, putative, nearly identical to SHEPHERD 
Supplementary Table 2. Gene Ontologies for 5000 unigenes represented on the Arabidopsis cDNA microarray used for expression profiling of the susceptible interaction between Ralstonia solanacearum BCCF401 and Arabidopsis thaliana Col-5.

\begin{tabular}{|c|c|c|}
\hline GO Category & Description & $\begin{array}{l}\text { \% of genes relative } \\
\text { to the whole } \\
\text { genome }\end{array}$ \\
\hline \multirow[t]{16}{*}{ Cellular Component } & other cellular components & \\
\hline & & 17 \\
\hline & other membranes & 17 \\
\hline & other intracellular components & 32 \\
\hline & other cytoplasmic components & 31 \\
\hline & chloroplast & 27 \\
\hline & nucleus & 24 \\
\hline & plastid & 27 \\
\hline & mitochondria & 44 \\
\hline & ribosome & 34 \\
\hline & cytosol & 31 \\
\hline & plasma membrane & 25 \\
\hline & cell wall & 18 \\
\hline & ER & 18 \\
\hline & Golgi apparatus & 18 \\
\hline & extracellular & 12 \\
\hline \multirow[t]{8}{*}{ Molecular Function } & other molecular functions & 12 \\
\hline & other enzyme activity & 19 \\
\hline & hydrolase activity & 21 \\
\hline & other binding & 20 \\
\hline & transferase activity & 23 \\
\hline & protein binding & 22 \\
\hline & DNA or RNA binding & 18 \\
\hline & transporter activity & 22 \\
\hline
\end{tabular}


transcription factor activity

structural molecule activity

nucleic acid binding 